\title{
Classification of Transportation Packaging and Dry Spent Fuel Storage System Components According to Importance to Safety
}

Manuscript Completed: January 1996

Date Published: February 1996

Prepared by

J. W. McConnell, Jr., A. L. Ayers, Jr., M. J. Tyacke

Idaho National Engineering Laboratory

Managed by the U.S. Department of Energy

Lockheed Martin Idaho Technologies

Idaho Falls, ID 83415

S. C. O'Connor, NRC Technical Monitor

Prepared for

Division of Industrial and Medical Nuclear Safety

Office of Nuclear Material Safety and Safeguards

U.S. Nuclear Regulatory Commission

Washington, DC 20555-0001

NRC Job Code J5052 


\section{DISCLAMMER}

Portions of this document may be illegible in electronic image products. Images are produced from the best available original document. 


\begin{abstract}
This report provides a graded approach for classification of components used in transportation packaging and dry spent fuel storage systems. This approach provides a method for identifying the classification of components according to importance to safety within transportation packagings and dry spent fuel storage systems. Record retention requirements are discussed to identify the documentation necessary to validate that the individual components were fabricated in accordance with their assigned classification. A review of the existing regulations pertaining to transportation packagings and dry storage systems was performed to identify current requirements. The general types of transportation packagings and dry storage systems were identified. Discussions were held with suppliers and fabricators of packagings and storage systems to determine current practices. The methodology used in this report is based on Regulatory Guide 7.10, Establishing Quality Assurance Programs for Packaging Used in the Transport of Radioactive Material. This report also includes a list of generic components for each of the general types of transportation packagings and spent fuel storage systems. The safety importance of each component is discussed, and a classification category is assigned.
\end{abstract}

Job Code J5052 - Classification of Components According to Importance to Safety 



\section{CONTENTS}

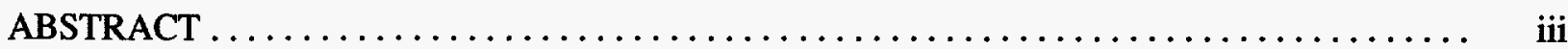

EXECUTIVE SUMMARY $\ldots \ldots \ldots \ldots \ldots \ldots \ldots \ldots \ldots \ldots \ldots \ldots \ldots \ldots \ldots \ldots \ldots \ldots \ldots \ldots \ldots$

1. INTRODUCTION $\ldots \ldots \ldots \ldots \ldots \ldots \ldots \ldots \ldots \ldots \ldots \ldots \ldots \ldots \ldots \ldots \ldots \ldots$

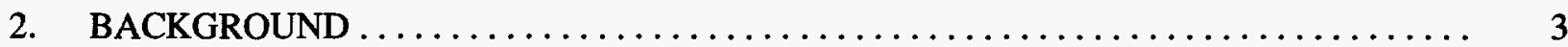

3. CLASSIFICATION CATEGORIES $\ldots \ldots \ldots \ldots \ldots \ldots \ldots \ldots \ldots \ldots \ldots \ldots \ldots \ldots$

4. QUALITY ASSURANCE RECORD RETENTION $\ldots \ldots \ldots \ldots \ldots \ldots \ldots \ldots \ldots \ldots \ldots$

4.1 Category A Components $\ldots \ldots \ldots \ldots \ldots \ldots \ldots \ldots \ldots \ldots \ldots \ldots \ldots \ldots \ldots \ldots \ldots \ldots$

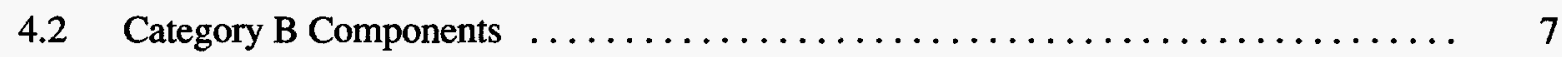

4.3 Category $\mathrm{C}$ Components $\ldots \ldots \ldots \ldots \ldots \ldots \ldots \ldots \ldots \ldots \ldots \ldots \ldots$

5. TRANSPORTATION PACKAGINGS $\ldots \ldots \ldots \ldots \ldots \ldots \ldots \ldots \ldots \ldots \ldots \ldots \ldots \ldots$

$5.1 \quad$ Packaging for LSA Shipments $\ldots \ldots \ldots \ldots \ldots \ldots \ldots \ldots \ldots \ldots \ldots \ldots \ldots \ldots \ldots \ldots \ldots$

5.1.1 Category A Items $\ldots \ldots \ldots \ldots \ldots \ldots \ldots \ldots \ldots \ldots \ldots \ldots \ldots \ldots \ldots$

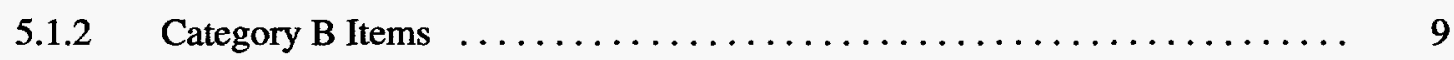

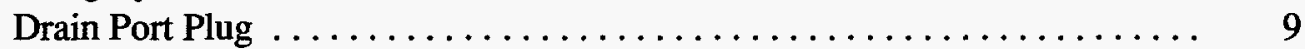

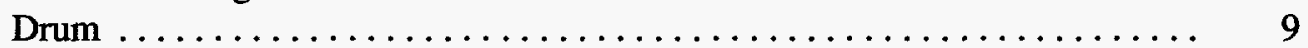

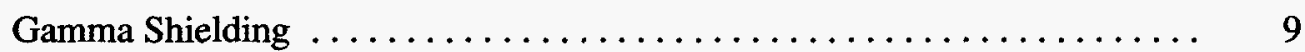

Lifting Lugs, Trunnions, and Attachments ............... 9

Lifting/Tiedown Hardware $\ldots \ldots \ldots \ldots \ldots \ldots \ldots \ldots \ldots \ldots \ldots \ldots . \ldots \ldots$

Pressure Relief Device $\ldots \ldots \ldots \ldots \ldots \ldots \ldots \ldots \ldots \ldots \ldots \ldots \ldots \ldots, 11$

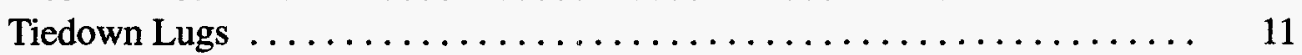

Vent and Drain Port Plug and Pressure Relief Device Seals ......... 11

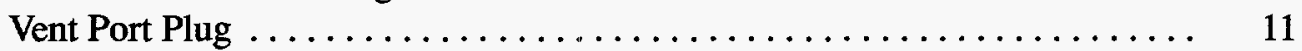

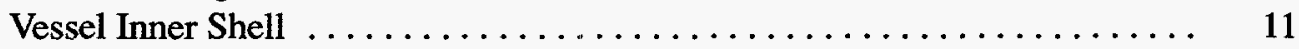

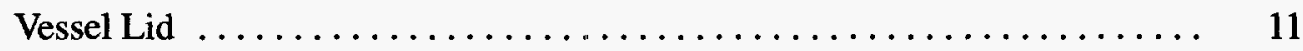

Vessel Lid Closure Hardware $\ldots \ldots \ldots \ldots \ldots \ldots \ldots \ldots \ldots \ldots \ldots \ldots \ldots$

Vessel Lid Seal . . . . . . . . . . . . . . . . . . . . . . . . . . . . 11

Vessel Outer Shell .............................. 11

Vessel Shell Bottom Head ............................ 12

Vessel Shell Upper Head $\ldots \ldots \ldots \ldots \ldots \ldots \ldots \ldots \ldots \ldots \ldots \ldots \ldots \ldots \ldots$

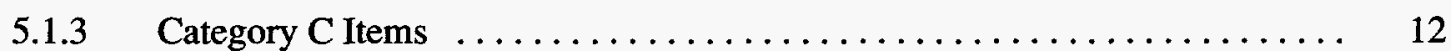

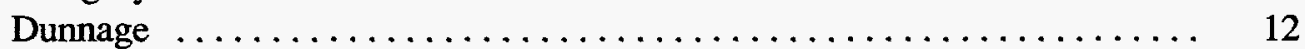

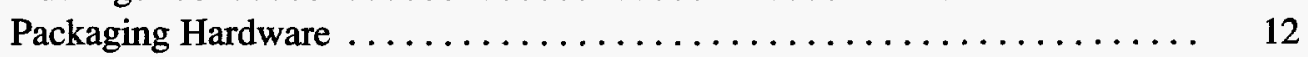

Protective Cover $\ldots \ldots \ldots \ldots \ldots \ldots \ldots \ldots \ldots \ldots \ldots \ldots \ldots \ldots, 12$

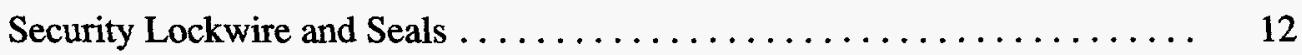

Skids/Forklift Channels . . . . . . . . . . . . . . . 12 
5.2 Packaging for Type A (Fissile) Shipments $\ldots \ldots \ldots \ldots \ldots \ldots \ldots \ldots \ldots \ldots$

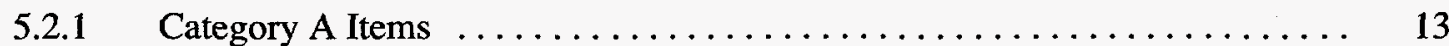

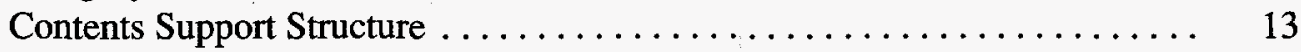

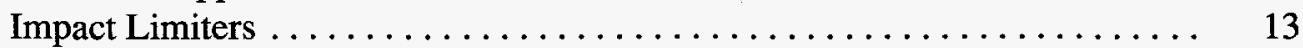

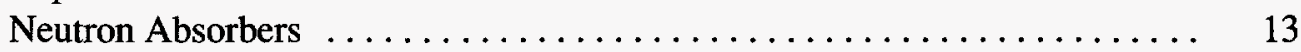

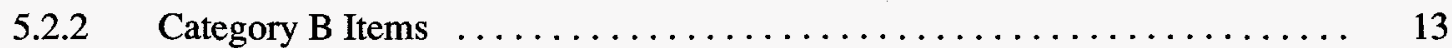

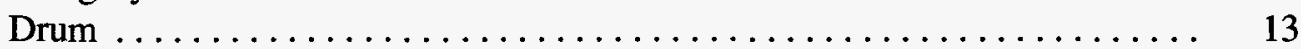

Lifting Lugs, Trunnions, and Attachments ................ 13

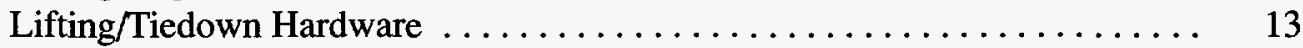

Vessel Inner Shell . . . . . . . . . . . . . . . . . . . . . . . 16

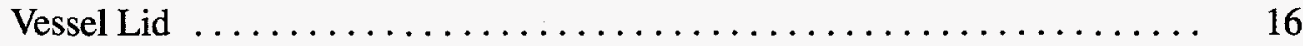

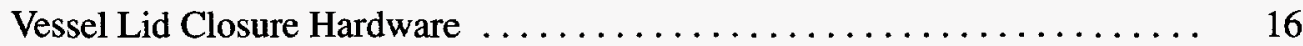

Vessel Lid Seal ............................... 16

Vessel Outer Shell ............................. 16

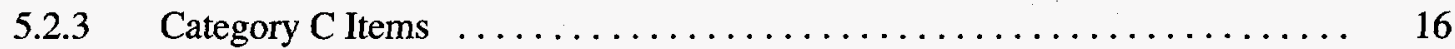

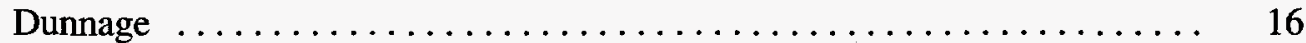

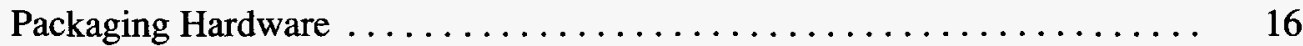

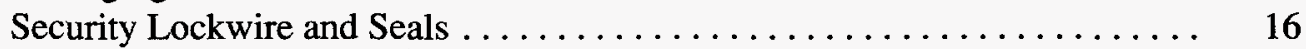

Skids/Forklift Channels . . . . . . . . . . . . . . . . . . . 16

5.3 Packaging for Type B (Normal Form) Shipments $\ldots \ldots \ldots \ldots \ldots \ldots \ldots \ldots \ldots$

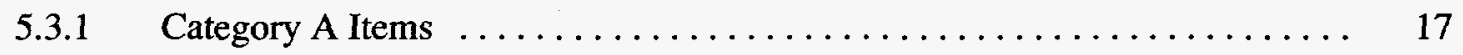

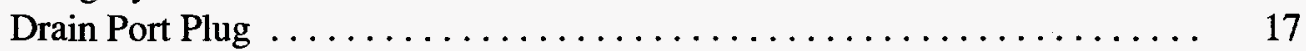

Impact Limiters . . . . . . . . . . . . . . . . . . . . . . . . 17

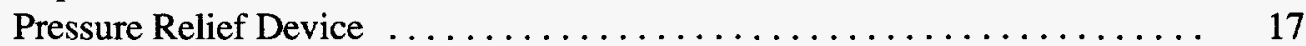

Temperature Control Components ................... 17

Vent and Drain Port Plug and Pressure Relief Device Inner Seals ... . . . . . 17

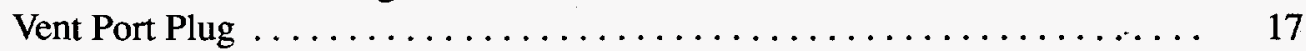

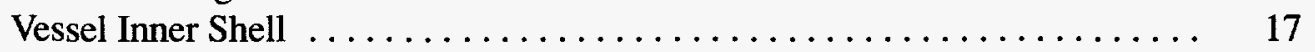

Vessel Lid ................................... 17

Vessel Lid Closure Hardware $\ldots \ldots \ldots \ldots \ldots \ldots \ldots \ldots \ldots \ldots \ldots . \ldots \ldots$

Vessel Lid Inner Seal . . . . . . . . . . . . . . . . . . . . . 19

Vessel Shell Bottom Head . . . . . . . . . . . . . . . . . . . . . . 19

Vessel Shell Upper Head . . . . . . . . . . . . . . . . . . . . . . 19

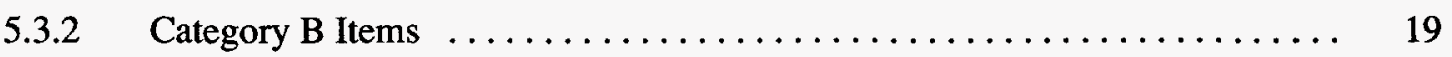

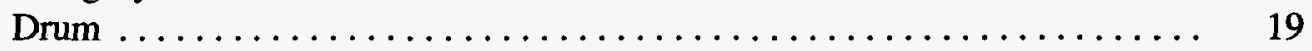

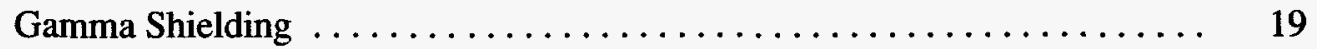

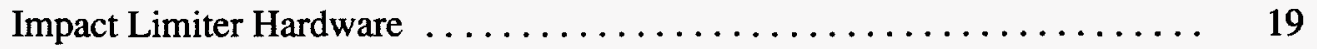

Leak Check Port Plug and Seal ..................... 20

Lifting Lugs, Trunnions, and Attachments ................ 20

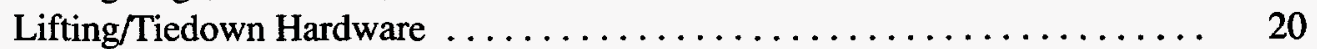

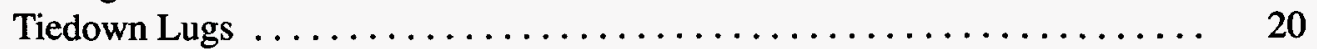

Vessel Outer Shell ........................... 20

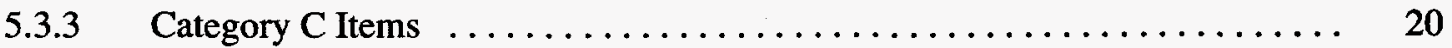

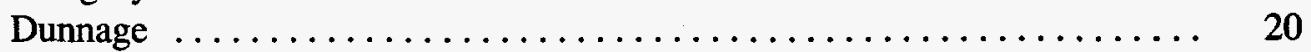




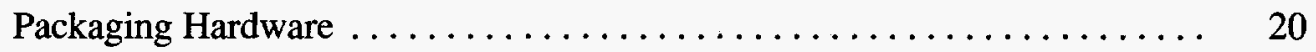

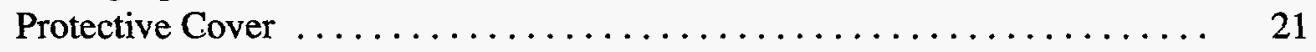

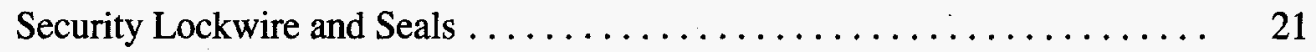

Skids/Forklift Channels . . . . . . . . . . . . . . . . . . . . 21

Vent and Drain Port Plug and Pressure Relief Device Outer Seals ...... 21

Vent, Drain and Leak Check Port Plug Cover Plates .............. 21

Vessel Lid Outer Seal ............................ 21

5.4 Packaging for Type B (Special Form) Shipments $\ldots \ldots \ldots \ldots \ldots \ldots \ldots \ldots \ldots \ldots$

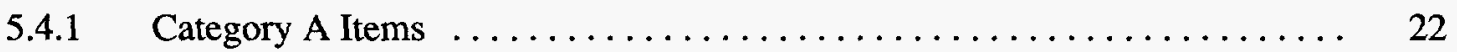

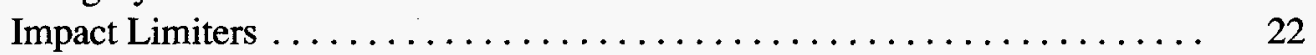

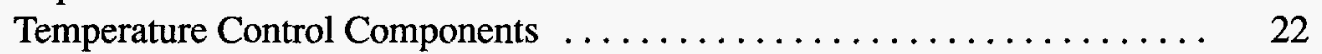

Vessel Inner Shell ............................... 22

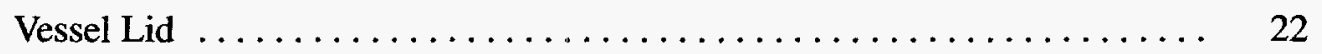

Vessel Lid Closure Hardware . . . . . . . . . . . . . . . . . 22

Vessel Shell Bottom Head . . . . . . . . . . . . . . . . . . . . . 25

Vessel Shell Upper Head ......................... 25

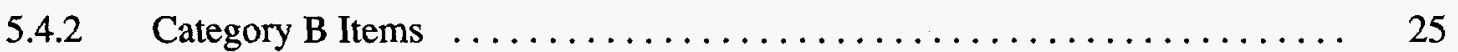

Drain Port Plug .................................. 25

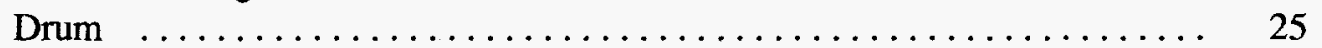

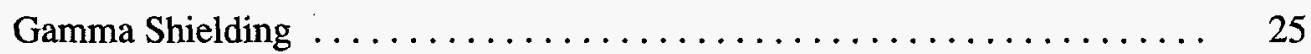

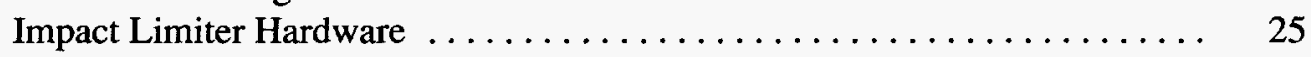

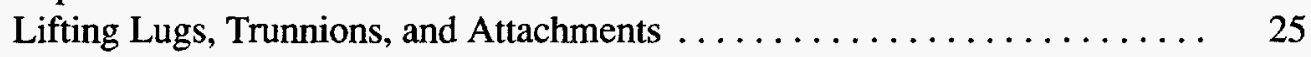

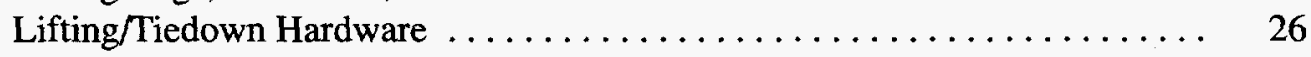

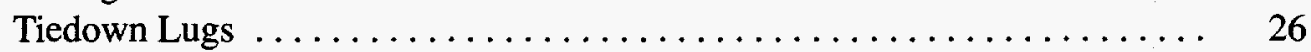

Vent and Drain Port Plug and Pressure Relief Device Seals $\ldots . \ldots \ldots \ldots .26$

Vessel Lid Seal ................................. 26

Vessel Outer Shell ............................ 26

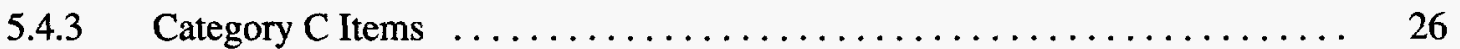

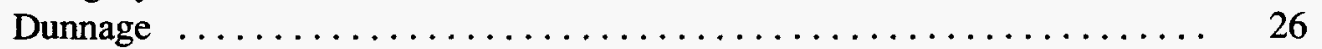

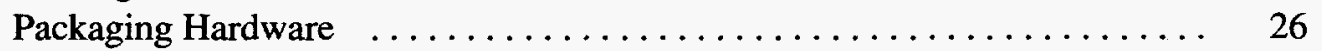

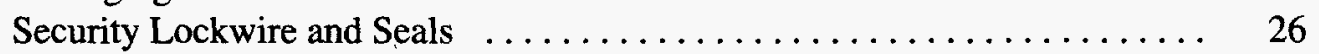

Skids/Forklift Channels . . . . . . . . . . . . . . . . $6 \ldots \ldots \ldots .26$

5.5 Packaging for Type B (Fissile) Shipments $\ldots \ldots \ldots \ldots \ldots \ldots \ldots \ldots \ldots \ldots \ldots$

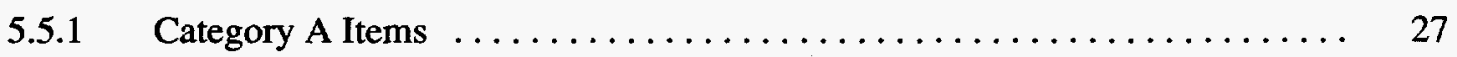

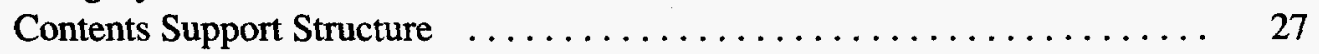

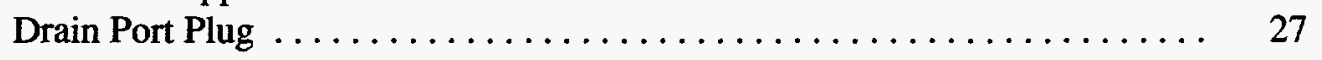

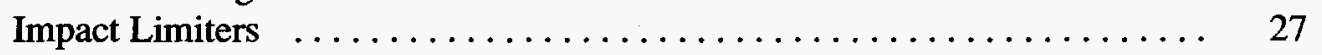

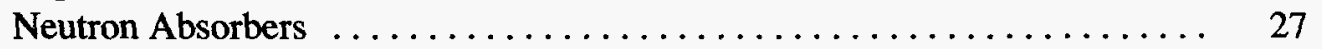

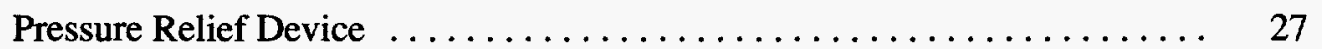

Temperature Control Components ............................ 27

Vent and Drain Port Plug and Pressure Relief Device Inner Seals . . . . . . 27

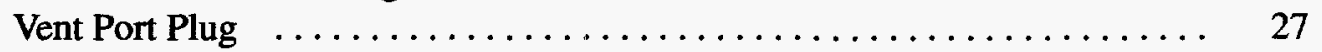

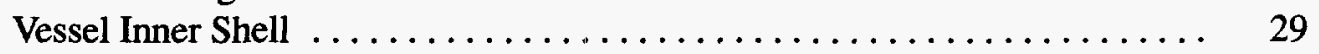

Vessel Lid ............................... 29 
Vessel Lid Closure Hardware $\ldots \ldots \ldots \ldots \ldots \ldots \ldots \ldots \ldots \ldots \ldots . \ldots \ldots$

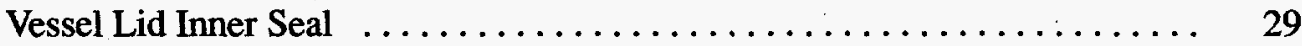

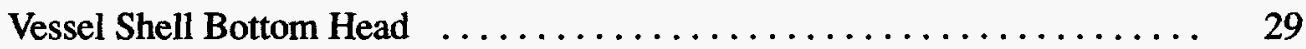

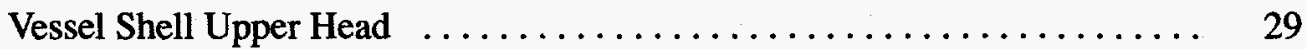

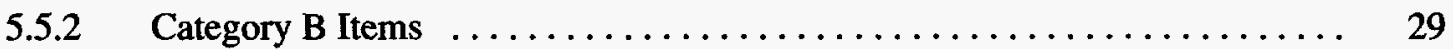

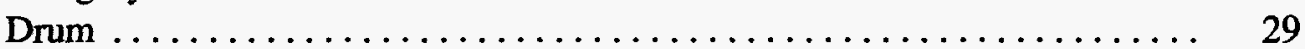

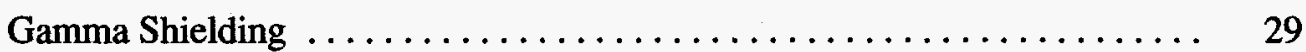

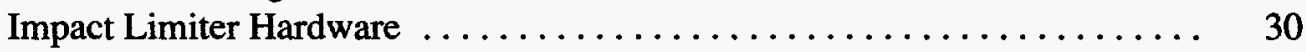

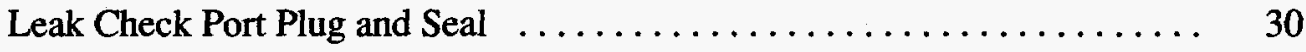

Lifting Lugs, Trunnions, and Attachments $\ldots \ldots \ldots \ldots \ldots \ldots \ldots \ldots . \ldots \ldots$

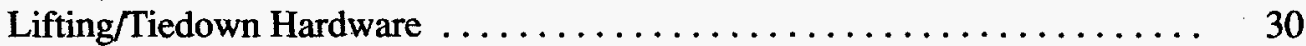

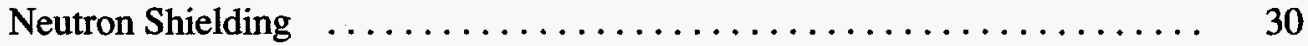

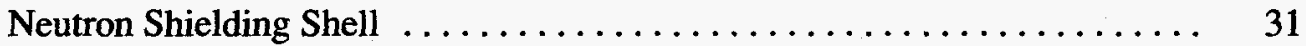

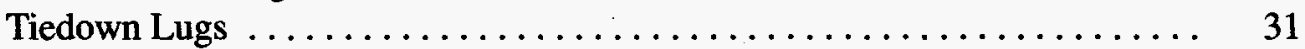

Vessel Outer Shell $\ldots \ldots \ldots \ldots \ldots \ldots \ldots \ldots \ldots \ldots \ldots \ldots \ldots \ldots \ldots \ldots$

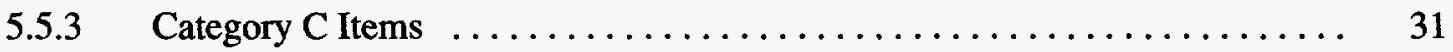

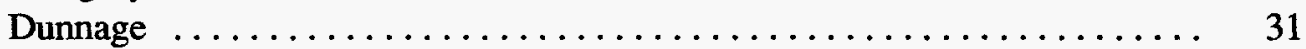

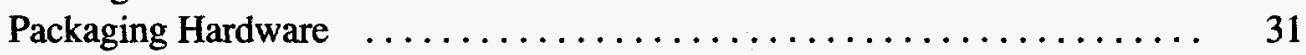

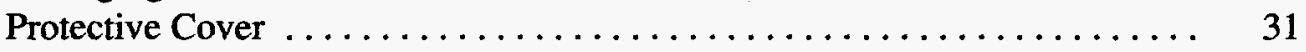

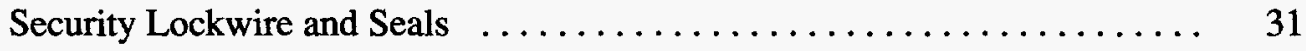

Skids/Forklift Channels .......................... 31

Vent and Drain Port Plug and Pressure Relief Device Outer Seals $\ldots \ldots \ldots 31$

Vent, Drain, and Leak Check Port Plug Cover Plates $\ldots \ldots \ldots \ldots \ldots \ldots . \ldots 32$

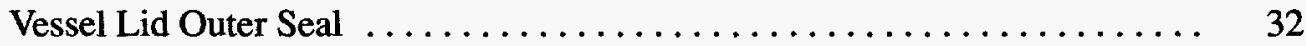

6. DRY SPENT FUEL STORAGE SYSTEMS $\ldots \ldots \ldots \ldots \ldots \ldots \ldots \ldots \ldots \ldots \ldots \ldots \ldots \ldots \ldots$

6.1 Metal Shielded Type Storage Systems $\ldots \ldots \ldots \ldots \ldots \ldots \ldots \ldots \ldots \ldots \ldots \ldots \ldots \ldots \ldots$

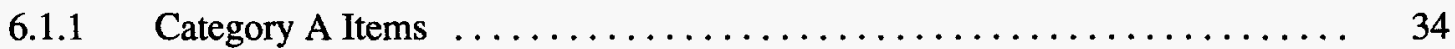

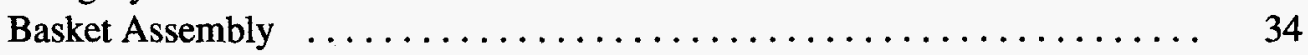

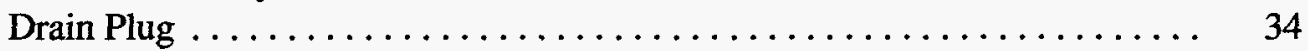

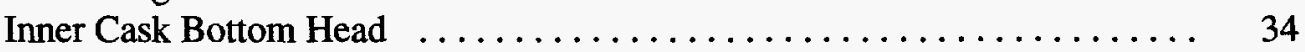

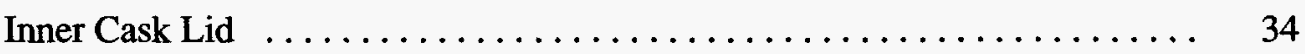

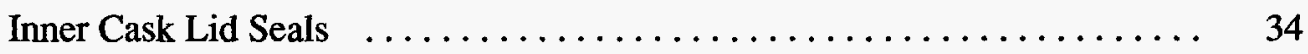

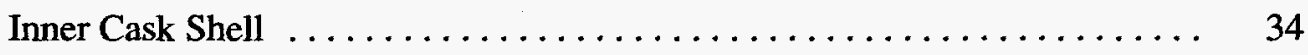

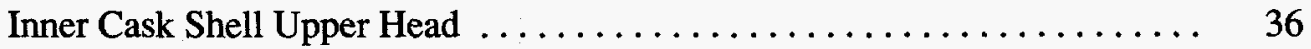

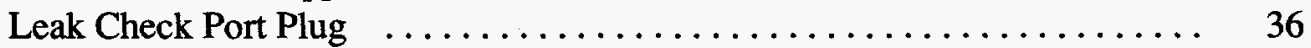

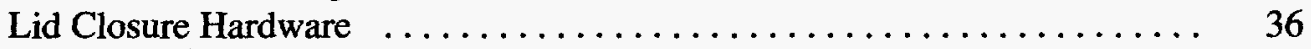

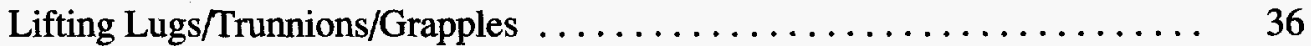

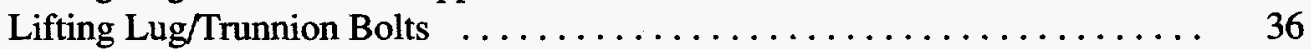

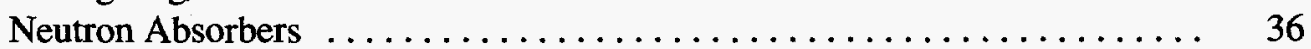

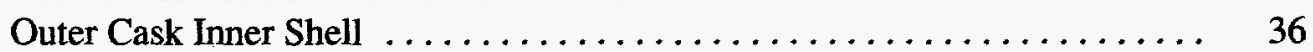

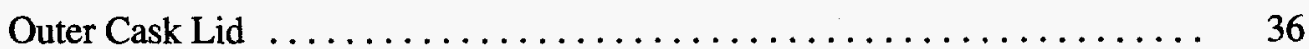

Outer Cask Lid Seals . . . . . . . . . . . . . . . . . . . . 37

Outer Cask Shell Bottom Head $\ldots \ldots \ldots \ldots \ldots \ldots \ldots \ldots \ldots \ldots \ldots . \ldots \ldots \ldots$

Outer Cask Shell Upper Head $\ldots \ldots \ldots \ldots \ldots \ldots \ldots \ldots \ldots \ldots \ldots . \ldots \ldots \ldots \ldots$

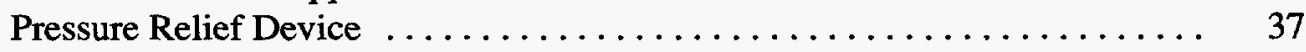


Temperature Control Components $\ldots \ldots \ldots \ldots \ldots \ldots \ldots \ldots \ldots \ldots \ldots . \ldots \ldots$

Vent and Drain Plug and Pressure Relief Device Seals ........... 37

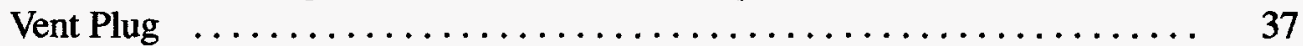

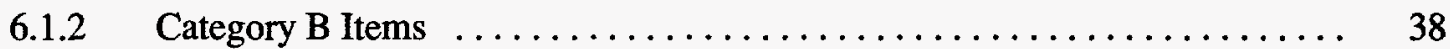

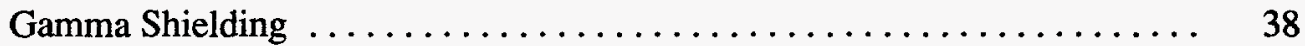

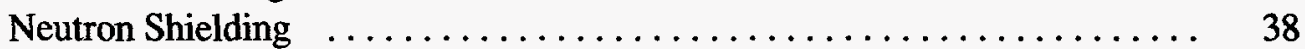

Outer Cask Outer Shell $\ldots \ldots \ldots \ldots \ldots \ldots \ldots \ldots \ldots \ldots \ldots \ldots \ldots$

Transfer Cask .................................... 38

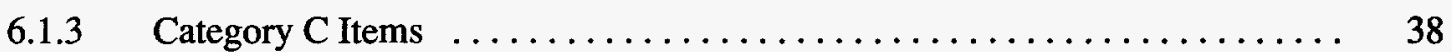

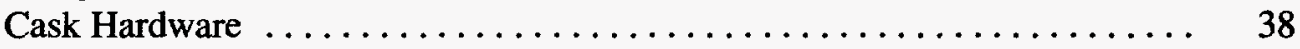

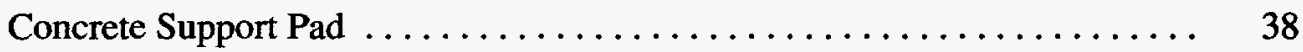

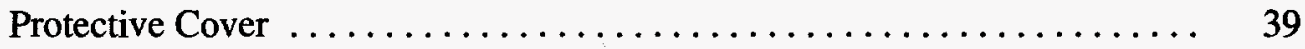

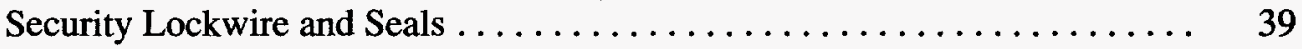

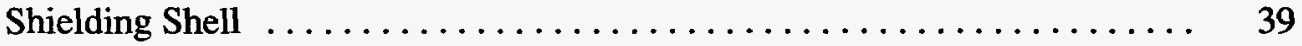

6.2 Concrete Shielded Type Storage Systems $\ldots \ldots \ldots \ldots \ldots \ldots \ldots \ldots \ldots \ldots \ldots \ldots$

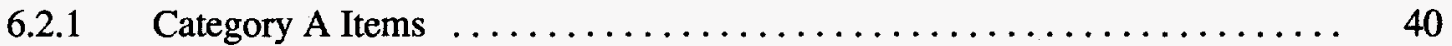

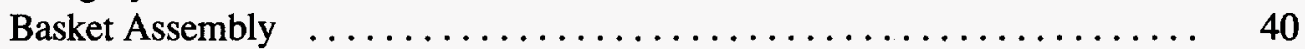

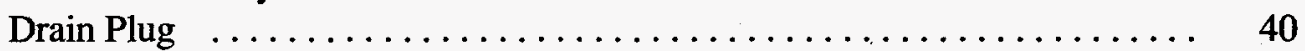

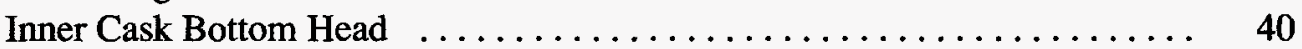

Inner Cask Lid . . . . . . . . . . . . . . . $40 \ldots \ldots \ldots \ldots \ldots . \ldots \ldots$

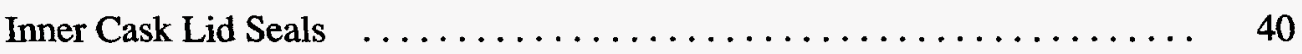

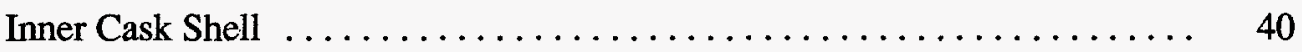

Inner Cask Shell Upper Head $\ldots \ldots \ldots \ldots \ldots \ldots \ldots \ldots \ldots \ldots \ldots \ldots .40$

Leak Check Port Plug $\ldots \ldots \ldots \ldots \ldots \ldots \ldots \ldots \ldots \ldots \ldots, 40$

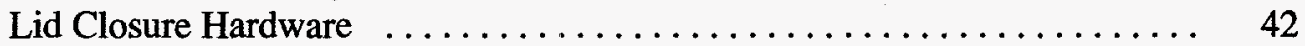

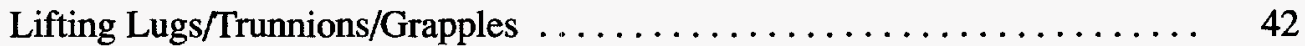

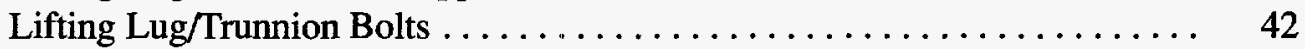

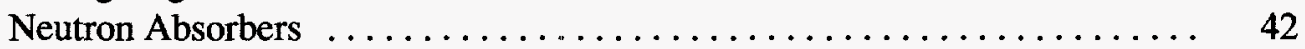

Pressure Relief Device ........................... 42

Vent and Drain Plug and Pressure Relief Device Seals $\ldots \ldots \ldots \ldots \ldots \ldots 42$

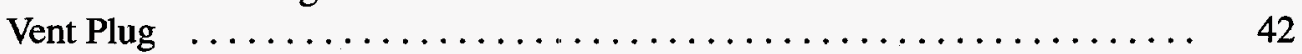

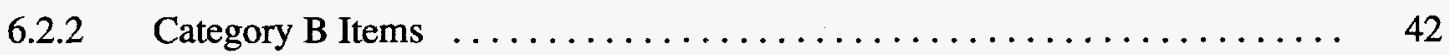

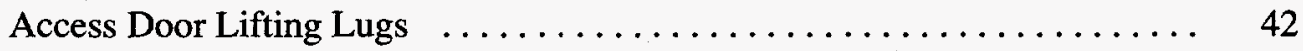

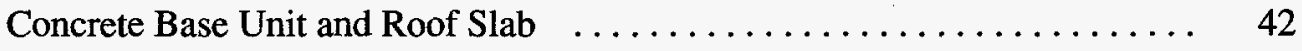

Concrete Structure Access Bolts $\ldots \ldots \ldots \ldots \ldots \ldots \ldots \ldots \ldots \ldots \ldots, 42$

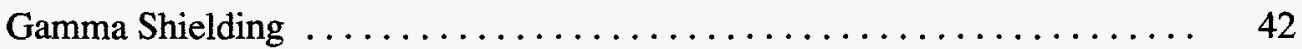

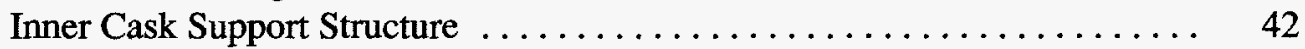

Inner Cask Top Shield Plug $\ldots \ldots \ldots \ldots \ldots \ldots \ldots \ldots \ldots \ldots \ldots, 43$

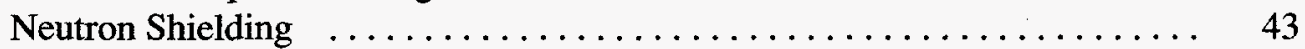

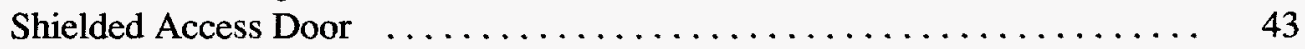

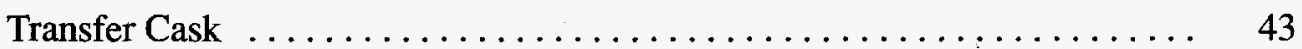

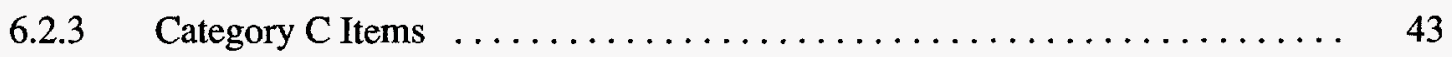

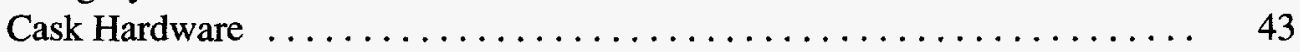

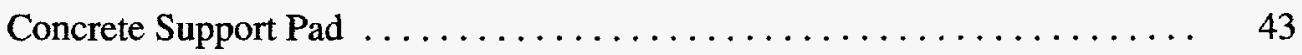




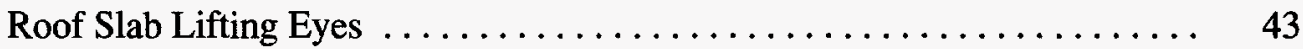

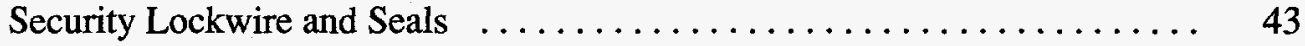

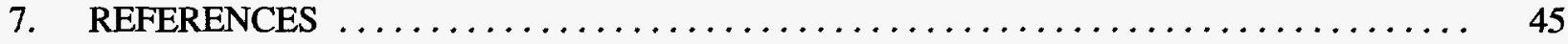

\section{FIGURES}

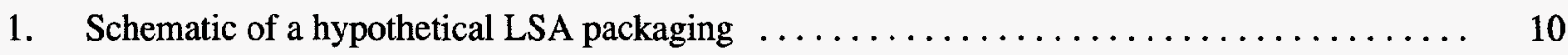

2. Schematic of a hypothetical Type A (Fissile) packaging $\ldots \ldots \ldots \ldots \ldots \ldots \ldots \ldots \ldots$

3. Schematic of a hypothetical Type A (Fissile) drum packaging $\ldots \ldots \ldots \ldots \ldots \ldots \ldots \ldots$

4. Schematic of a hypothetical Type B (Normal Form) activity packaging $\ldots \ldots \ldots \ldots$

5. Schematic of a hypothetical Type B (Special Form) packaging $\ldots \ldots \ldots \ldots \ldots \ldots \ldots$

6. Schematic of a hypothetical radiography device as Type B (Special Form) packaging $\ldots \ldots \quad 24$

7. Schematic of a hypothetical Type B (Fissile) packaging $\ldots \ldots \ldots \ldots \ldots \ldots \ldots \ldots \ldots$

8. Schematic of a hypothetical metal shielded type dry storage system $\ldots \ldots \ldots \ldots \ldots$

9. Schematic of a hypothetical concrete shielded type dry storage system $\ldots \ldots \ldots \ldots \ldots$

\section{TABLES}

1. Descriptions of transportation packagings and dry spent fuel storage systems $\ldots \ldots \ldots \ldots$. 2

2. Descriptions of Classification Categories A, B, and C $\ldots \ldots \ldots \ldots \ldots \ldots \ldots \ldots \ldots$

3. Definitions for primary function categories $\ldots \ldots \ldots \ldots \ldots \ldots \ldots \ldots \ldots \ldots \ldots$

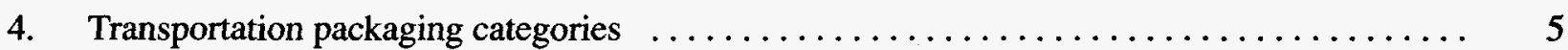

5. Classification categories for Transportation Packaging Categories I, II, and III components .. 33

6. Classification categories for dry spent fuel storage systems $\ldots \ldots \ldots \ldots \ldots \ldots \ldots \ldots$ 


\section{EXECUTIVE SUMMARY}

This report describes a method for determining the classification of components used in transportation packagings and dry spent fuel storage systems according to importance to safety. A review was performed of the rules, regulations, regulatory guidance, and various reports associated with the design, fabrication, and certification of transportation packagings and spent fuel storage systems. Discussions were held with several suppliers and fabricators of packagings and storage containers to establish current practices.

For the purposes of this report, transportation packagings are divided into five categories: (a) Low Specific Activity (LSA), (b) Type A
(Fissile), (c) Type B (Normal Form), (d) Type B (Special Form), and (e) Type B (Fissile). Also presented is a method for grouping dry spent fuel storage systems as either metal shielded type or concrete shielded type. Generic components are defined for each transportation packaging and spent fuel storage system.

The components in the packagings and storage systems were grouped into one of three classification categories in accordance with the principles outlined in Regulatory Guide 7.10. A discussion of the rationale for classification category assignment is presented in this report. Clarification of the quality assurance record requirements of Regulatory Guide 7.10 is also included. 


\section{Classification of Transportation Packagings and Dry Spent Fuel Storage System Components According to Importance to Safety}

\section{INTRODUCTION}

The U.S. Nuclear Regulatory Commission's (NRC's) Office of Nuclear Material Safety and Safeguards has established an inspection program for transportation packagings and dry spent fuel storage systems. This inspection program is designed to ascertain that transportation packagings and dry storage systems are designed, tested, fabricated, maintained, and used in accordance with requirements of Title 10 of the Code of Federal Regulations (CFR) Parts 71 and 72.1,2

10 CFR Part 71 provides for a graded approach to specifying quality assurance (QA) criteria for the development of transportation packagings. General QA guidance for transportation packagings has been provided in Regulatory Guide $7.10 .{ }^{3}$ However, the graded approach has been difficult to apply. There have been differences in interpreting the different classifications for various container components. In some cases, significant rework and component rejection have resulted from the differences in interpretations for applying the graded approach to transportation packagings and spent fuel storage systems.

To ensure consistency in interpreting the graded approach to assigning QA criteria, the NRC has requested the Idaho National Engineering Laboratory to investigate methods for apply- ing the graded approach to the following types of containers. Table 1 provides descriptions used to identify each container.

- $\quad$ Transportation packagings: Low Specific Activity (LSA), Type A (Fissile), Type B (Normal Form), Type B (Special Form), and Type B (Fissile)

- Dry spent fuel storage systems: Metal shielded type and concrete shielded type.

In a joint undertaking by the Idaho National Engineering Laboratory and the Office of Nuclear Material Safety and Safeguards, a system has been developed for identifying the safety classification of components on transportation packagings and spent fuel storage containers. This report documents the system and is provided in five sections: background, classification categories, quality assurance record retention, transportation packagings, and dry spent fuel storage systems. This document is limited to the design and fabrication of transport packagings and spent fuel storage containers. This report is to serve as a guide for determination of classification categories for transport packaging and storage cask components. Licensing submittal requirements specifying categories will be evaluated on an application-specific basis. 
Table 1. Descriptions of transportation packagings and dry spent fuel storage systems.

\begin{tabular}{|c|c|}
\hline Container Type & Description \\
\hline LSA & $\begin{array}{l}\text { A packaging designed to transport normal form radioactive material that } \\
\text { meets the requirements for low specific activity (LSA) and has a total } \\
\text { radioactivity greater than an } \mathrm{A}_{2}{ }^{\mathrm{a}} \text { quantity (e.g., low-level waste). }\end{array}$ \\
\hline Type A (Fissile) & $\begin{array}{l}\text { A packaging designed to transport fissile material that does not meet the } \\
\text { fissile material exemption standards in } 10 \mathrm{CFR} 71.53^{1} \text { and has a total } \\
\text { radioactivity that does not exceed an } \mathrm{A}_{1}^{\mathrm{a}} \text { or } \mathrm{A}_{2} \text { quantity (e.g., } \\
\text { unirradiated nuclear reactor fuel). }\end{array}$ \\
\hline Type B (Normal Form) & $\begin{array}{l}\text { A packaging designed to transport normal form radioactive material that } \\
\text { has a total activity greater than an } \mathrm{A}_{2} \text { quantity (e.g., waste material that } \\
\text { exceeds LSA concentration). }\end{array}$ \\
\hline Type B (Special Form) & $\begin{array}{l}\text { A packaging designed to transport special form radioactive material that } \\
\text { has a total activity greater than an } A_{1} \text { quantity (e.g., radiography } \\
\text { sources). }\end{array}$ \\
\hline Type B (Fissile) & $\begin{array}{l}\text { A packaging designed to transport fissile material that does not meet the } \\
\text { fissile material exemption standards in } 10 \text { CFR } 71.53^{1} \text { and has a total } \\
\text { radioactivity greater than an } A_{1} \text { or an } A_{2} \text { quantity (e.g., irradiated nuclear } \\
\text { reactor fuel). }\end{array}$ \\
\hline $\begin{array}{l}\text { Metal shielded type dry } \\
\text { spent fuel storage system }\end{array}$ & $\begin{array}{l}\text { A system designed to store dry spent nuclear reactor fuel at an } \\
\text { independent spent fuel storage installation or monitored retrievable } \\
\text { storage facility. A cask may be comprised of a containment system and } \\
\text { several layers of shielding metal. }\end{array}$ \\
\hline $\begin{array}{l}\text { Concrete shielded type } \\
\text { dry spent fuel storage } \\
\text { system }\end{array}$ & $\begin{array}{l}\text { A system designed to store dry spent nuclear reactor fuel at an } \\
\text { independent spent fuel storage installation or monitored retrievable } \\
\text { storage facility. Spent fuel is placed inside a cask that is placed inside a } \\
\text { concrete structure. }\end{array}$ \\
\hline
\end{tabular}




\section{BACKGROUND}

The QA provisions in 10 CFR Part $71,{ }^{1}$ Subpart $H$, and 10 CFR Part $72,{ }^{2}$ Subpart G, specify that companies that are authorized by the NRC to receive, possess, use, or transfer licensed material shall identify and provide control over material and components covered by an NRC-approved QA program to an extent consistent with their safety importance. The current document used by many transportation packaging and spent fuel container manufacturers and suppliers to categorize materials and components according to the level of safety importance is Regulatory Guide $7.10^{3}$

The graded approach to a QA program for transportation packagings contained in Appendix A of Regulatory Guide $7.10^{3}$ refers to the QA criteria in generalized terms (e.g., the role of components used in the packagings or storage systems for the protection of public health and safety) and is subject to a wide range of interpretations. NRC inspections identified that some suppliers and fabricators believe that they accomplish more than is necessary, while others are not even aware of a graded approach to the safety categorization of materials and components. This leads to controlling the fabrication, procurement, and docu- mentation activities inconsistently from one organization to the next. Since the application of the QA requirements to similar components of packagings and dry storage systems for different suppliers and fabricators varies widely, a significant difference in the definition of the documents that are maintained as QA records has also been noted. Specifically, some suppliers and fabricators maintain all documentation as QA records, while others maintain almost none.

A number of supplier and fabricator companies were contacted to determine how QA requirements were defined for various packaging and storage system components. The companies contacted included suppliers and fabricators of both transportation packagings and dry spent fuel storage systems. Based on the contacts, it was determined that most suppliers and fabricators review each component of the packaging and dry storage system. Quality requirements are assigned to each individual component consistent with the component function and safety requirements. The requirements are documented on drawings, component lists, or procurement documents. Some components may have a less stringent review based on less safety significance. 


\section{CLASSIFICATION CATEGORIES}

Appendix A of Regulatory Guide $7.10^{3}$ presents a method of classification of various components in a transportation packaging. Each component of a transportation packaging is first identified as either "important to safety" or "not important to safety." Then, components that are considered "important to safety" are further categorized into one of three classification categories (A, B, or C), depending on that component's importance to safety. Table 2 presents descriptions of Classification Categories A, B, and C.

Information has been developed on transportation packaging components and the importance of those components to the overall safety offered by packaging. Many of these data were used to produce the guidance in this document. A list of typical generic components was developed for each container category. The list was intended to have sufficient detail to allow grouping of all components and provide sufficient latitude for considerable variation in design of containers. The primary function of each component was determined in accordance with the definitions in Table 3. Table 4 presents definitions of Transportation Packaging Categories I, II, and III as defined in Regulatory Guide 7.11.4

For each container type, a classification category was assigned to components based on the rationale presented in Sections 5 and 6, and the classification categories defined in Table 2. Table 5 (in Section 5) presents the assigned classification categories for the components of five transportation packagings. Table 6 (in Section 6) presents classification categories of components for two dry spent fuel storage system configurations. The figures in Sections 5 and 6 illustrate components for each generic cask type and where the component is located in the cask assembly. The tables serve as general guidance for determining the classification category of a component. The assignment of a category different from

Table 2. Descriptions of Classification Categories A, B, and C. ${ }^{\mathrm{a}}$

\begin{tabular}{|c|c|c|}
\hline $\begin{array}{c}\text { Classification } \\
\text { Category }\end{array}$ & $\begin{array}{c}\text { Importance to } \\
\text { Safety }\end{array}$ & Description \\
\hline A & $\begin{array}{l}\text { Critical to safe } \\
\text { operation }\end{array}$ & $\begin{array}{l}\text { Category A items include structures, components, and systems } \\
\text { whose failure could directly result in a condition adversely } \\
\text { affecting public health and safety. The failure of a single item } \\
\text { could cause loss of primary containment leading to release of } \\
\text { radioactive material, loss of shielding, or unsafe geometry } \\
\text { compromising criticality control. }\end{array}$ \\
\hline B & $\begin{array}{l}\text { Major impact on } \\
\text { safety }\end{array}$ & $\begin{array}{l}\text { Category B items include structures, components, and systems } \\
\text { whose failure or malfunction could indirectly result in a } \\
\text { condition adversely affecting public health and safety. The } \\
\text { failure of a Category B item, in conjunction with the failure of } \\
\text { an additional item, could result in an unsafe condition. }\end{array}$ \\
\hline $\mathrm{C}$ & $\begin{array}{l}\text { Minor impact on } \\
\text { safety }\end{array}$ & $\begin{array}{l}\text { Category } C \text { items include structures, components, and systems } \\
\text { whose failure or malfunction would not significantly reduce the } \\
\text { packaging effectiveness and would not be likely to create a } \\
\text { situation adversely affecting public health and safety. }\end{array}$ \\
\hline
\end{tabular}

a. From Appendix A of Regulatory Guide 7.10 (Reference 3). 
Table 3. Definitions for primary function categories.

\begin{tabular}{|c|c|}
\hline Function & Description \\
\hline Containment & $\begin{array}{l}\text { The components and supporting materials that are incorporated into the container } \\
\text { design for the purpose of retaining the radioactive material during normal and } \\
\text { accident conditions. }\end{array}$ \\
\hline Criticality control & $\begin{array}{l}\text { The components and supporting materials that are incorporated into the container } \\
\text { design for the purpose of maintaining the contents in a subcritical configuration } \\
\text { during normal and accident conditions. }\end{array}$ \\
\hline Shielding & $\begin{array}{l}\text { The components and supporting materials that are incorporated into the container } \\
\text { design for the purpose of reducing radiation emitted by the contents during normal } \\
\text { and accident conditions. }\end{array}$ \\
\hline Heat transfer & $\begin{array}{l}\text { The components and supporting materials that are incorporated into the container } \\
\text { design for the purpose of decay heat removal under normal conditions and } \\
\text { protecting temperature-sensitive components (e.g., lead shielding and seals) under } \\
\text { accident conditions. }\end{array}$ \\
\hline Structural integrity & $\begin{array}{l}\text { The components and supporting materials that are incorporated into the container } \\
\text { design for the purpose of maintaining the structure in a safe condition during } \\
\text { normal and accident conditions. }\end{array}$ \\
\hline Operations support & $\begin{array}{l}\text { The components and supporting materials that are incorporated into the container } \\
\text { design for the purpose of routine use (e.g., loading, unloading, use maintenance, } \\
\text { monitoring, and transporting). }\end{array}$ \\
\hline
\end{tabular}

Table 4. Transportation packaging categories. ${ }^{a}$

\begin{tabular}{|c|c|c|c|}
\hline & Category I & Category II & Category III \\
\hline \multicolumn{2}{|l|}{ LSA } & $\begin{array}{l}\text { Greater than } 30,000 \mathrm{Ci} \text { or } \\
\text { greater than } 3,000 \mathrm{~A}_{1}{ }^{\mathrm{b}} \text { or } \\
\text { greater than } 3,000 \mathrm{~A}_{2}{ }^{\mathrm{b}}\end{array}$ & $\begin{array}{l}\text { Less than } 30,000 \mathrm{Ci} \text { and } \\
\text { less than } 3,000 \mathrm{~A}_{1} \text { and less } \\
\text { than } 3,000 \mathrm{~A}_{2}\end{array}$ \\
\hline $\begin{array}{l}\text { Special } \\
\text { Form }\end{array}$ & $\begin{array}{l}\text { Greater than } 3,000 \mathrm{~A}_{1} \text { or } \\
\text { greater than } 30,000 \mathrm{Ci}\end{array}$ & $\begin{array}{l}\text { Between } 3,000 \mathrm{~A}_{1} \text { and } \\
30 \mathrm{~A}_{1} \text { and not greater than } \\
30,000 \mathrm{Ci}\end{array}$ & $\begin{array}{l}\text { Less than } 30 \mathrm{~A}_{1} \text { and less } \\
\text { than } 30,000 \mathrm{Ci}\end{array}$ \\
\hline $\begin{array}{l}\text { Normal } \\
\text { Form }\end{array}$ & $\begin{array}{l}\text { Greater than } 3,000 \mathrm{~A}_{2} \text { or } \\
\text { greater than } 30,000 \mathrm{Ci}\end{array}$ & $\begin{array}{l}\text { Between } 3,000 \mathrm{~A}_{2} \text { and } \\
30 \mathrm{~A}_{2} \text { and not greater than } \\
30,000 \mathrm{Ci}\end{array}$ & $\begin{array}{l}\text { Less than } 30 \mathrm{~A}_{2} \text { and less } \\
\text { than } 30,000 \mathrm{Ci}\end{array}$ \\
\hline \multicolumn{4}{|c|}{ a. From Regulatory Guide 7.11 (Reference 4). } \\
\hline \multicolumn{4}{|c|}{$\begin{array}{l}\text { b. Defined in } 10 \text { CFR Part } 71.4 \text { as the maximum activity of radioactive material permitted in a Type A package } \\
\text { (in Ci) where } A_{1} \text { applies to Special Form and } A_{2} \text { applies to Normal Form. Values of } A_{1} \text { and } A_{2} \text { for specific } \\
\text { radionuclides are listed in Appendix } A \text { of } 10 \text { CFR Part } 71 \text {. }\end{array}$} \\
\hline
\end{tabular}


those indicated in the tables is acceptable. However, the final classification of each container component needs to be justified and documented by the classifier. We have found that identifying the classification category of components on the design documentation is a method that has proven very helpful in licensing and inspection. The applicant may wish to provide such information at licensing submittal.

Materials used in fabrication are determined in the design stage through the intended use requirements of the package. However, the quality of those materials is specified by the code or standard that is applied to the component. In addition, the codes will often impose controls on the procurement, receipt, storage, and use of the materials. The container materials may include bulk material such as metal plate, sheet, castings, weld metal, and forgings. Also included are items fabricated by subtier vendors (e.g., seals, bolts, pressure relief valves, rupture disks, and special closure assemblies). Typically, traceability of material, control of chemical and physical properties of the materials, and isolation of the material from nonconforming materials are used to ensure proper fabrication. Control of the quality of the component is often required over several subtier vendors. The precise requirements are determined by the code or standard to which the component is built. However, there may be considerable differences in material requirements between components within a single container type and between similar components of different container categories.

Fabrication requirements may vary between components within a single container type and between similar components of different container categories in a manner similar to the materials of construction. For example, welds that attach or join components are the same classification category as the higher level component unless a lower classification can be justified. Welds that join a component (such as a cyliner longitudinal seam weld) are the same classification as the components they are a part of. Many requirements for processes (e.g., welding and heat treating) are defined within the code used for construction. However, for some special processes (e.g., pouring gamma shielding), no specific code exists, and approved procedures are needed to perform the task. Each procedure requires qualification to ensure conformance to requirements.

As in materials and fabrication, quality standards may vary between components within a single container type and between similar components of different container categories. Quality standards for a Category A component are significantly more rigorous than for a Category $\mathrm{C}$ component. Because there may be no available manufacturer with a Category A program for materials such as foam, honeycomb, or wood (used in impact limiters); concrete or lead (used in shielding); and polymers (used in seals), packaging or cask vendors will be allowed to use dedicated manufacturer's programs to procure Category A components. This will place more responsibilities on the designers to specify the most important material properties and characteristics and on the manufacturers to comply with those specifications. 


\section{QUALITY ASSURANCE RECORD RETENTION}

Sections 2 and 3 of this report describe how the classification categories of individual components are assigned based on the component's primary function and its importance to overall safety. This section summarizes the record retention requirements that are necessary to document that the individual components were fabricated in accordance with their assigned classification.

QA record retention requirements are specified in 10 CFR Part 71, Sections 71.91(c) and 71.135 and in 10 CFR Part 72, Section 72.174. These sections identify certain documents that need to be maintained as permanent QA records. Permanent QA records are defined in 10 CFR Part 71 as those documents that are to be retained for 3 years after the life of the transportation packaging to which they apply, while 10 CFR Part 72 defines those documents that are to be retained for the life of the storage cask license.

Although each design has unique characteristics that will determine the QA documents to be maintained as permanent records, certain documents to be maintained as permanent $\mathrm{QA}$ records are common to both transportation packagings and dry storage systems. These documents may include design, fabrication, and assembly records; results of reviews, inspections, tests, and audits; results of monitoring work performance and materials analyses; and results of maintenance, modification, and repair activities.

The following Category A, B, and C quality records ${ }^{3}$ need to be maintained in conjunction with the record retention requirements identified above.

\subsection{Category A Components}

- Design documentation to verify review and approval of new designs and modifications to existing designs.

- Results of reviews, audits, and monitoring of work performance.
- Documentation to verify review and approval of qualified vendors.

- Procurement documents and material certifications from qualified vendors to verify traceability.

- Qualifications of personnel with responsibilities such as welder, nondestructive examination inspector, lead QA auditor, and quality control inspector.

- Approved procedures used for design and fabrication activities such as welding, inspection, auditing, and procurement.

- List of equipment used and documentation to verify calibration.

- Inspection and test results for qualification and production activities, identification of inspectors, type of observation, acceptance criteria, and action taken in connection with any noted deficiencies.

- A commercial parts dedication program ${ }^{5,6}$ may be used, but all supporting documentation needs to be maintained.

\subsection{Category B Components}

- Design documentation to verify review and approval of new designs and modifications to existing designs.

- Results of reviews, audits, and monitoring of work performance.

- Qualifications of personnel with responsibilities such as welder, nondestructive examination inspector, lead QA auditor, and quality control inspector.

- Approved procedures used for design and fabrication activities such as welding, inspection, auditing, and procurement.

- List of equipment used and documentation to verify calibration. 
- Inspection and test results for qualification and production activities, identification of inspectors, type of observation, acceptance criteria, and action taken in connection with any noted deficiencies.

- A commercial parts dedication program ${ }^{5,6}$ may be used, but all supporting documentation needs to be maintained.

\subsection{Category C Components}

- QA records are not required to be maintained. 


\section{TRANSPORTATION PACKAGINGS}

This section provides detailed descriptions of the components that make up transportation packagings. Table 5 (located at the end of this section) presents the classification categories for the components of those packagings. The assignment of classifications different from those in the table is acceptable but must be justified as discussed in Section 3. The table is organized by (a) transportation packaging Categories I, II, and III (defined in Table 4), and (b) radioactive material contents.

\subsection{Packaging for LSA Shipments}

This section discusses considerations for assigning classification categories to components for an LSA packaging. This is a packaging designed to transport normal form radioactive material that meets the requirements for LSA and has a total radioactivity greater than an $\mathrm{A}_{2}$ quantity (e.g., low-level waste). Figure 1 depicts a conceptual schematic of the components used in this type of packaging. The radioactive material is first placed in an inner container such as a drum or liner, which provides a secondary barrier to radioactive release. The outer vessel or packaging provides the primary barrier to the release of radioactive materials. When there is no inner container, the outer vessel may have a different function.

\subsubsection{Category A Items}

There are no Category A items on LSA packaging.

\subsubsection{Category B Items}

Drain Port Plug. Drain ports are provided for removal of water from LSA packaging. A plug is provided to close each drain port. The plugs also are used to maintain packaging containment under normal and accident conditions.

Drum. When used as an outer shell, the drum provides support for the contents in both normal and accident conditions. In order for the radioactive material to be released, both outer drum and inner container must be breached. That requires two failures.

Gamma Shielding. Gamma shielding is used to reduce external radiation doses to levels acceptable for transport. Lead and various steels have been used in the past for gamma radiation shielding. The presence and effectiveness of the shielding is subject to testing during fabrication of the packaging. The shielding usually performs no function other than shielding and its presence is sufficient to satisfy its function. The shielding is usually enclosed by the inner and outer shells and, as a solid, is not subject to removal during normal conditions of transport. Under many accident conditions, the shielding remains in place and still performs the intended function. However, some materials (i.e., lead) may melt in the event of a fire. Given that an analysis demonstrates that the expansion of the lead will not rupture the package containment, the molten material will remain in place unless the outer shell is breached. Therefore, it would require two failures, loss of the outer shell and melting of the shielding, to prevent the shielding from performing its intended function. The requirements of a specific design may dictate that a higher classification category be assigned to gamma shielding in some circumstances.

\section{Lifting Lugs, Trunnions, and Attach-} ments. LSA packages may be lifted using special lugs, trunnions, or special attachments. The lifting lugs and attachments are attached to the packaging but have a limited safety function during transportation. Failure of a lug will not allow a breach of containment.

The lifting lugs are also used inside facilities to lift the package from a transport skid and place the package into a loading station. For a facility, those steps may be a critical lift requiring a much higher level of safety significance than would be found in transport. Quality inspections similar to those of Category A, design loads in excess of transportation requirements, and post-load test inspectability are issues that may influence the category actually placed upon the lugs. 


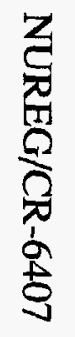

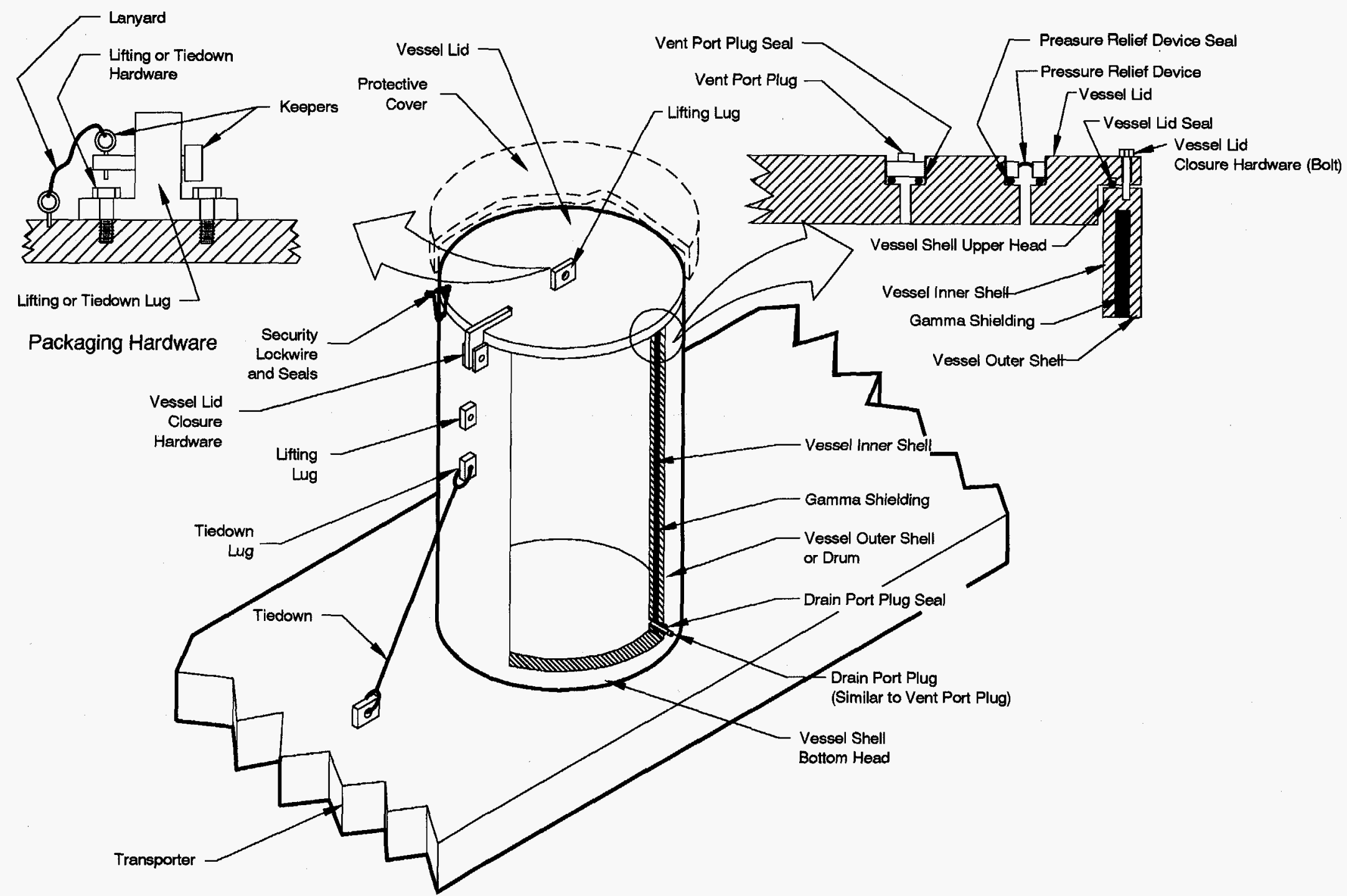

Figure 1. Schematic of a hypothetical LSA packaging. 
Lifting/Tiedown Hardware. Bolts might be used to attach either lugs or special hardware to an LSA package. The bolts should have the same category as the lifting lug. Like the lifting lugs or lifting attachments, the bolts may have more rigorous quality requirements for use inside a facility than for transportation.

Pressure Relief Device. The pressure relief device is used to limit the internal pressure of LSA packaging. This device could include rupture disks or pressure relief valves. In addition, this device is also used to maintain packaging containment under normal and accident conditions.

Tiedown Lugs. A transportation packaging is held to a vehicle with tiedowns and other similar devices. The packaging will often have attachments and lugs for connection of the tiedowns. The lugs are not necessary for containment, criticality control, or shielding in either normal or accident conditions.

Vent and Drain Port Plug and Pressure Relief Device Seals. A seal is usually provided for vent and drain port plugs and pressure relief devices. The seals are used to maintain containment in the package under normal and accident conditions.

Vent Port Plug. LSA packagings are equipped with a vent port. The port may be used for venting the packaging during loading operations. Gas may be purged through the port for control of gas carried contamination, radioactive gases, or gases generated by the contents of the package. Some packagings require the displacement of interior gas to remove or install the lid. A plug is provided to close the vent during transport. The plug is used to maintain packaging containment under normal and accident conditions.

Vessel Inner Shell. The vessel inner shell is the interior wall of the packaging and is typically welded to the vessel shell bottom head and the vessel shell upper head. The vessel inner shell is part of containment under normal conditions. A single failure would not release radioactive material outside the packaging.
LSA packagings consist of an outer shell enclosing an inner container, which serves the function of a vessel inner shell. In order for radioactive material to be released, both the outer packaging and the inner container must be breached. That requires two failures. The vessel may have a different function when no inner container is used.

Vessel Lid. The vessel lid provides containment and often shielding for the upper end of the packaging under normal conditions. The vessel lid will have closure bolt holes and sealing surfaces. Vent port, leak check port, and a pressure relief device are usually installed in the vessel lid. Attachments or threaded bolt holes are provided for rigging used to remove the vessel lid from the packaging. A single failure of the vessel lid would not release radioactive material from the package without a failure of the inner container. The vessel may have a different function when no inner container is used.

Vessel Lid Closure Hardware. Lids are assembled to the packaging with a number of bolts. The bolts are used to maintain containment in the package under normal and accident conditions. The failure of a single closure bolt is not expected to release radioactive material to uncontrolled areas. Other closure assemblies might be used for closing this type of packaging.

Vessel Lid Seal. A single seal is usually provided on LSA packaging lids. The seal is used to maintain containment in the package under normal and accident conditions.

Vessel Outer Shell. The vessel outer shell provides structural support for the LSA package. The shell is typically welded to the vessel shell bottom head and the vessel shell upper head. The shell often is the outer wall of gamma shielding. The vessel outer shell usually is used to maintain configuration of the package in an accident condition. Many packaging designs provide features that mitigate the consequences of failure of the vessel outer shell. For example, breaching the vessel outer shell still requires a breach of the vessel inner shell before containment is breached. 
Vessel Shell Bottom Head. The vessel shell bottom head provides containment and often shielding for the lower end of the package under normal conditions. The vessel shell bottom head may be welded to the vessel inner shell and the vessel outer shell. Shielding materials may extend to the vessel shell bottom head and in some packaging designs may be located inside the head. If so, the head may prevent draining of certain shield materials in the unlikely event of a postaccident fire. A single failure of this component would not release radioactive material from the package without a failure of the inner container. The vessel may have a different function when no inner container is used.

Vessel Shell Upper Head. The vessel shell upper head provides containment and shielding for the upper cylindrical end of the packaging. The head may have sealing surfaces for the package and bolt threads for closure of the package lid. The head is typically welded to the vessel inner shell and often to the vessel outer shell. Shielding materials may extend to the head. If so, the head may prevent draining some types of shield materials in the unlikely event of a postaccident fire. A single failure of this component would not release radioactive material from the packaging without a failure of the inner container. The vessel may have a different function when no inner container is used.

\subsubsection{Category C Items}

Dunnage. Dunnage is a packing material that is placed between the packaging and the contents to prevent movement of the contents during normal and sometimes accident transport conditions.
Dunnage in a package may be used to provide energy absorption and reduce the impact load. If the dunnage is required to reduce impact loading on the containment boundary, it is a higher category item.

Packaging Hardware. Keepers are often used as a redundant feature to prevent bolts and nuts from becoming unscrewed, pins from falling out, and lifting attachments from being improperly used. Small bolts and nuts, cotter pins, detent pins, and lockwires have been used for this function. Lanyards are often used to attach bolts and keepers to the packaging to prevent misplacement of the parts. The keepers and lanyards usually do not have a direct safety implication and will not cause containment failure, loss of criticality control, or reduction of shielding capabilities if not present.

Protective Cover. LSA packaging may have a protective cover and possibly some attachments. The cover serves to reduce accumulation of ice and dust from the surfaces of the package and has no safety function.

Security Lockwire and Seals. Security lockwire and seals are used in packaging to ensure that the contents shipped in the package are not tampered with. The function is a safeguard issue and not one of safety.

Skids/Forklift Channels. Sometimes, LSA packaging has a shipping skid that may be equipped with channels for use with a forklift. Like the lifting attachment, the skid (including forklift channels) may have more rigorous quality requirements for use inside a facility than for transportation. 


\subsection{Packaging for Type A (Fissile) Shipments}

This section discusses considerations for assigning classification categories to components for a Type A (Fissile) packaging. This is a packaging designed to transport fissile material that does not meet the fissile material exemption standards in 10 CFR Part $71.53^{1}$ and has a total radioactivity less than an $A_{1}$ or $A_{2}$ quantity (e.g., fresh, unirradiated nuclear reactor fuel). Figures 2 and 3 depict conceptual schematics of the components used in this type of packaging.

\subsubsection{Category A Items}

Contents Support Structure. The contents supports are used to maintain the package in a critically safe condition in normal and accident conditions. The contents supports may be either an integral function of the outer shell and lid assemblies or be a separate internal structure.

Impact Limiters. Impact limiters are fabricated from energy-absorbing materials that limit mechanical damage in an accident. The function of the energy absorber is to crush during the accident. In crushing of the energy absorber, the impact limiter is performing its function, and crushing is not considered to be a failure of the material. Therefore, the properties of the materials used for energy absorption are important to the proper function of the impact limiter and to the safety of the package. Many different types of materials may be used as energy absorbers. In the past, plastic foams, metal honeycombs, and wood have been used. The impact limiter may be an assembly made up of the energy-absorbing material and a shell covering the material, which provides additional strength, crush resistance, and other properties. In such cases, the individual parts of the impact limiter assembly may have a lower classification category. Failure of the impact limiter would result in a high potential for containment failure. In addition, failure of the impact limiter may also result in a loss of criticality control under an accident condition.
Neutron Absorbers. Neutron absorbers are often used for control of criticality in Type A (Fissile) packaging. In other packages, castable neutron absorbers may be used. The absorber material is required for criticality control under normal and accident conditions.

\subsubsection{Category B Items}

Drum. When used as an outer shell, the drum provides support for the contents in both normal and accident conditions. In order for the radioactive material to be released, both the outer drum and inner drum or container must be breached. That requires two failures.

Lifting Lugs, Trunnions, and Attachments. Type A (Fissile) packages are usually lifted and attached to transportation skids through an attachment specifically designed for lifting. Lifting eyes, eye bolts, and installable assemblies are examples that might be used. Those attachments have a limited safety function during transportation. Failure of a properly designed attachment will not allow a breach of containment or criticality. The impact limiters would have to fail and either the containment boundary of the contents be breached or the contents supports be damaged to cause a significant failure.

The lifting attachments are also used inside facilities to lift the package from a transport skid and place the package into a loading station. For a facility, those steps may be a critical lift requiring a higher level of safety significance than would be found in transport. Quality inspection requirements, design loads in excess of transportation requirements, and post-load test inspectability are issues that may influence the category actually placed upon the lifting attachments.

Lifting/Tiedown Hardware. Sometimes, bolts are used in a lifting attachment. The bolts shall have the same category as the lifting attachment. Like the lifting attachment, the bolts may have more rigorous quality requirements for use inside a facility than for transportation. 


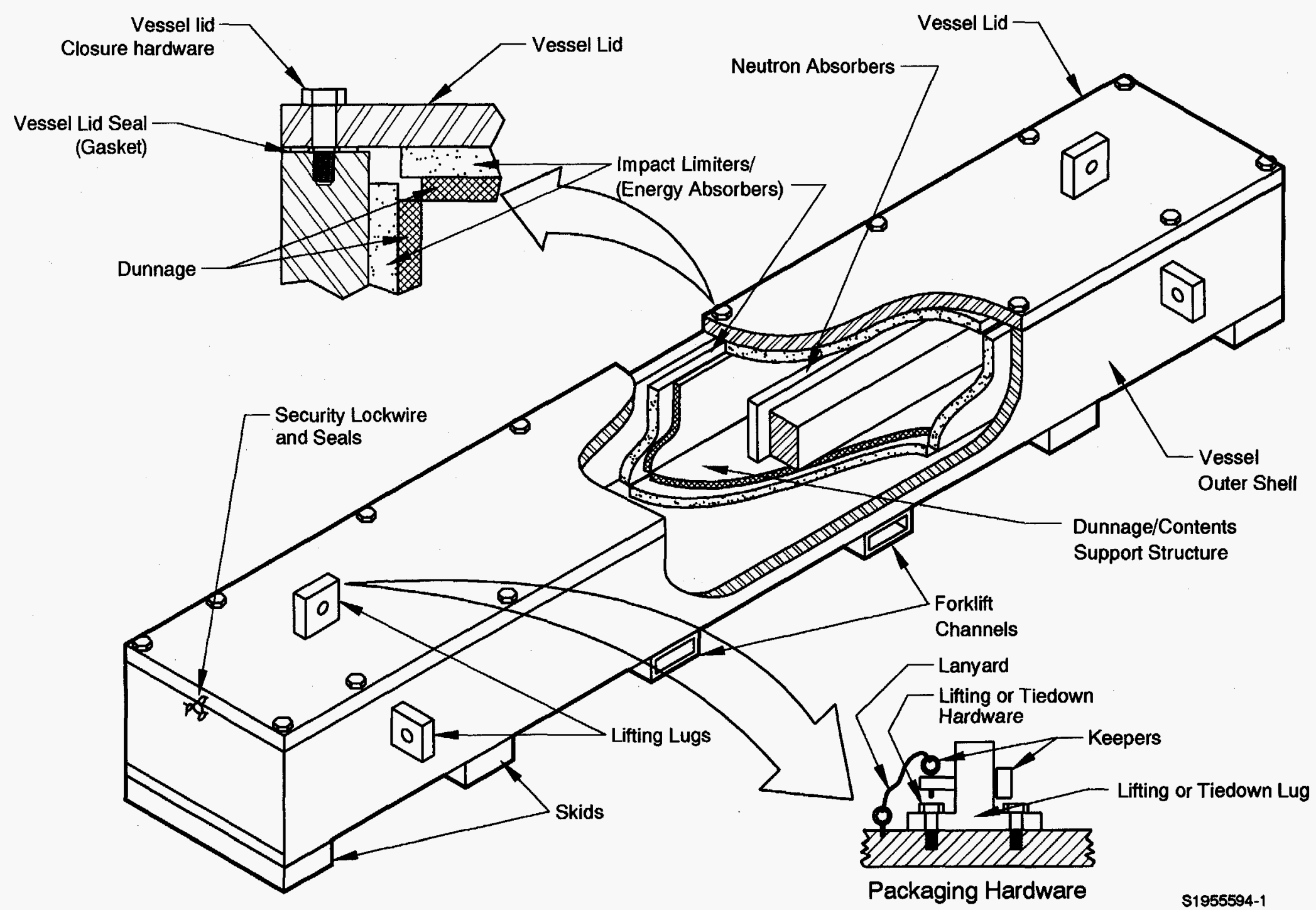

Figure 2. Schematic of a hypothetical Type A (Fissile) packaging. 


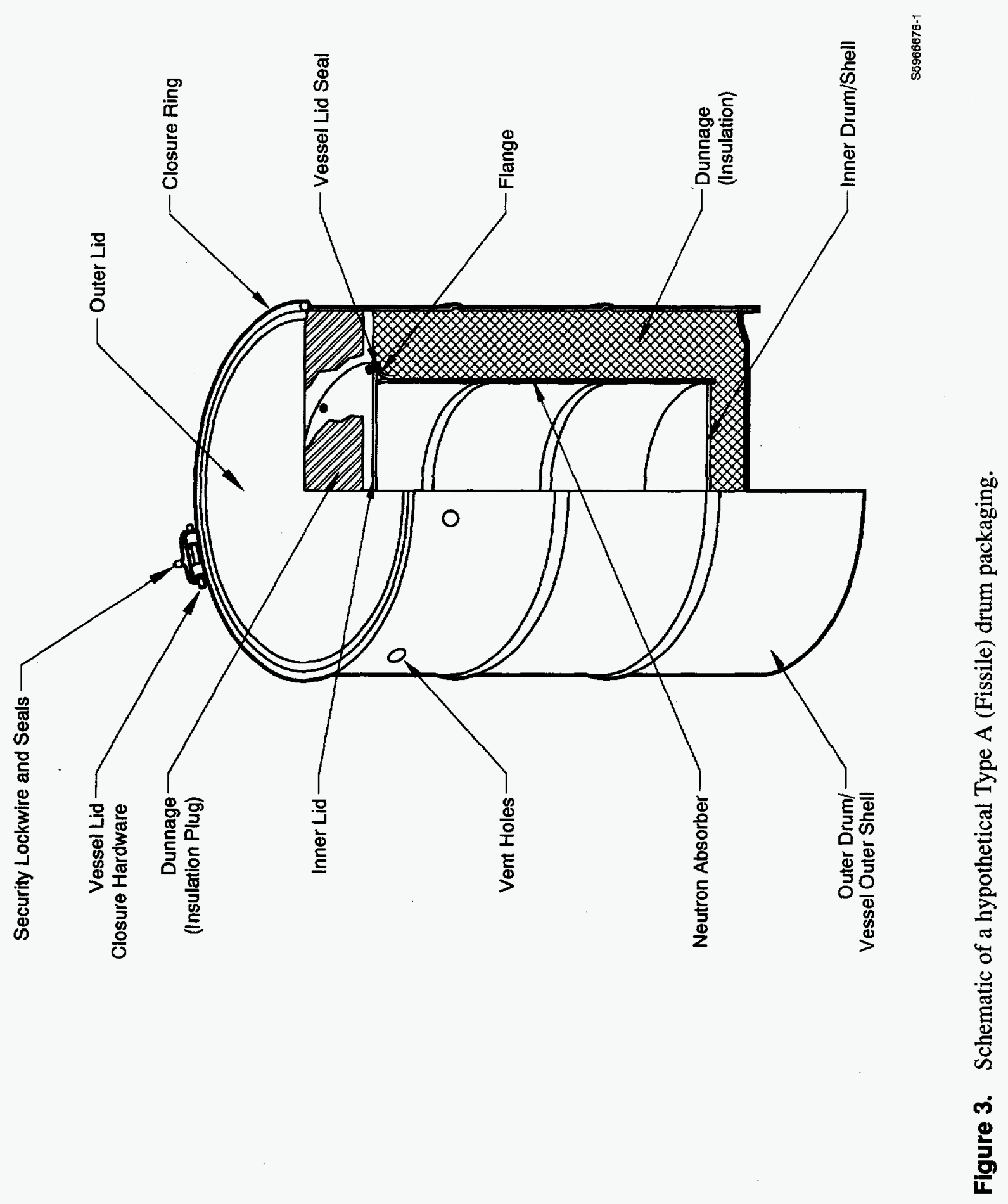


Vessel Inner Shell. The vessel inner shell in many Type A (Fissile) drum packagings is a second drum as shown in Figure 3. That inner drum consists of the lower head, side wall, flange, lid, and lid seal. The lid may be held in place with bolts or a closure ring. In order for radioactive material to be released, both the inner drum and outer drum must be breached.

Vessel Lid. As in the vessel outer shell, two failures are required for radioactive material to be released through the lid.

Vessel Lid Closure Hardware. As in the vessel outer shell and lid, two failures are required for radioactive material to be released through failure of either the closure bolts or a closure assembly.

Vessel Lid Seal. Seals are used to reduce dust and moisture on the contents of the package. The seals are not required for containment of the radioactive material in the contents of the packaging under either normal or accident conditions.

Vessel Outer Shell. The Type A (Fissile) package usually transports a content that is both low in external radiation and is provided with its own containment. One example of this is a fresh nuclear reactor fuel assembly. The fuel cladding provides the containment for decay products of the fuel. Therefore, as in the case of the drum (Figure 3), the outer shell provides support for the contents in both the normal and accident condition. In order for radioactive material to be released, both the shell and the containment must be breached. That requires two failures.

\subsubsection{Category C Items}

Dunnage. Dunnage is a packing material that is placed between the packaging and the contents to prevent movement of the contents during normal and sometimes accident transport conditions. Dunnage in a package may be required to provide energy absorption and reduce the impact load. If the dunnage is required to reduce impact loading on the containment boundary, it is a higher category item.

Packaging Hardware. Keepers are often used as a redundant feature to prevent bolts and nuts from becoming unscrewed, pins from falling out, and lifting attachments from being improperly used. Small bolts and nuts, cotter pins, detent pins, and lockwires have been used for this function. Lanyards are often used to attach bolts and keepers to the packaging to prevent misplacement of the parts. The keepers and lanyards usually do not have a direct safety implication and will not cause containment failure, loss of criticality control, or reduction of shielding capabilities if not present.

Security Lockwire and Seals. Security lockwire and seals are used in packaging to ensure that the contents shipped in the package are not tampered with. The function is a safeguard issue and not one of safety.

Skids/Forklift Channels. Sometimes, Type A (Fissile) packaging has a shipping skid that may be equipped with channels for use with a forklift. Like the lifting attachment, the skid (including forklift channels) may have more rigorous quality requirements for use inside a facility than for transportation. 


\subsection{Packaging for Type B (Normal Form) Shipments}

This section discusses considerations for assigning classification categories to components for a Type B (Normal Form) packaging. This is a packaging designed to transport normal form radioactive material that has a total activity greater than an $A_{2}$ quantity (e.g., waste material that exceeds LSA concentration). Figure 4 depicts a conceptual schematic of the components used in this type of packaging.

\subsubsection{Category A Items}

Drain Port Plug. In some applications, Type B (Normal Form) packaging may be loaded under water. Drain ports are provided for removal of water from the packaging. A plug is provided to close each drain port. The plugs also are required to maintain packaging containment under normal and accident conditions.

Impact Limiters. Impact limiters are made up of a shell filled with energy-absorbing materials that limit mechanical damage in an accident. The function of the energy absorber is to crush during the accident. In crushing of the energy absorber, the impact limiter is performing its function, and crushing is not considered to be a failure of the material. Therefore, the properties of the materials used for energy absorption are important to the proper function of the impact limiter and to the safety of the package. Many different types of materials may be used as energy absorbers. In the past, plastic foams, metal honeycombs, and wood have been used. The shell is a metal skin that covers the energy-absorbing material and protects that material from minor damage and weather. In some cases, the shell may provide structural support to the impact limiter assembly. In such cases, the individual parts of the impact limiter assembly may have a lower classification category. Failure of the impact limiter may result in failure of containment due to structural damage of those components.

Pressure Relief Device. Pressure relief devices are used to limit the internal pressure of Type B (Normal Form) packaging. Those devices could include rupture disks or pressure relief valves. In addition, those devices also are required to maintain packaging containment under normal and accident conditions.

Temperature Control Components. Temperature control components may be required for packages to withstand an accident fire. Therefore, the packaging must prevent excessive heat from causing failure of the package under this extreme. Items such as fins, radiant heat shields, and insulation may be required to control temperature under accident conditions. These items may be required on Category I Type B (Normal Form) packaging but may not be required on Categories II and III Type B (Normal Form) packaging.

Vent and Drain Port Plug and Pressure Relief Device Inner Seals. Two seals are usually provided for each vent and drain port plug and pressure relief device. The inner seals are required for maintaining containment in the package under normal and accident conditions. The outer seals are addressed under Category $\mathrm{C}$ items.

Vent Port Plug. Many Type B (Normal Form) packagings may be equipped with a vent port. Gas may be purged through the port for control of gas carried contamination, radioactive gases, or gases generated by the contents of the package. Some packagings require the displacement of interior gas to remove or install the lid. A plug is provided to close the vent during transport. The plug is required to maintain packaging containment under normal and accident conditions.

Vessel Inner Shell. The vessel inner shell is the interior wall of the packaging and is typically welded to the vessel shell bottom head and the vessel shell upper head. The vessel inner shell is part of the containment under normal and accident conditions. A single failure could release radioactive material outside the packaging.

Vessel Lid. The vessel lid provides containment and often shielding for the upper end of the packaging under normal and accident conditions. The vessel lid will have closure bolt holes and sealing surfaces. Vent port, leak check port, and a 


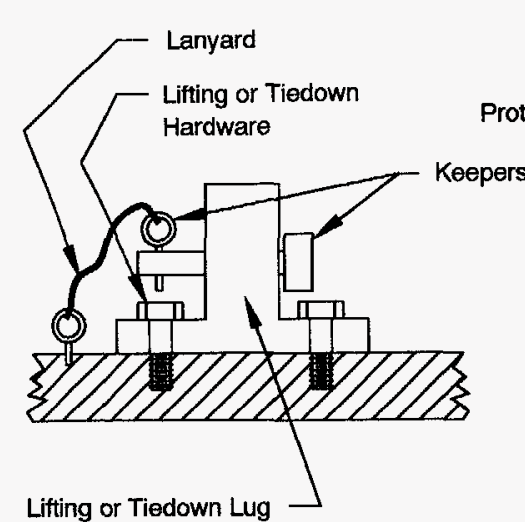

Litting or Tiedown Lug

Packaging Hardware

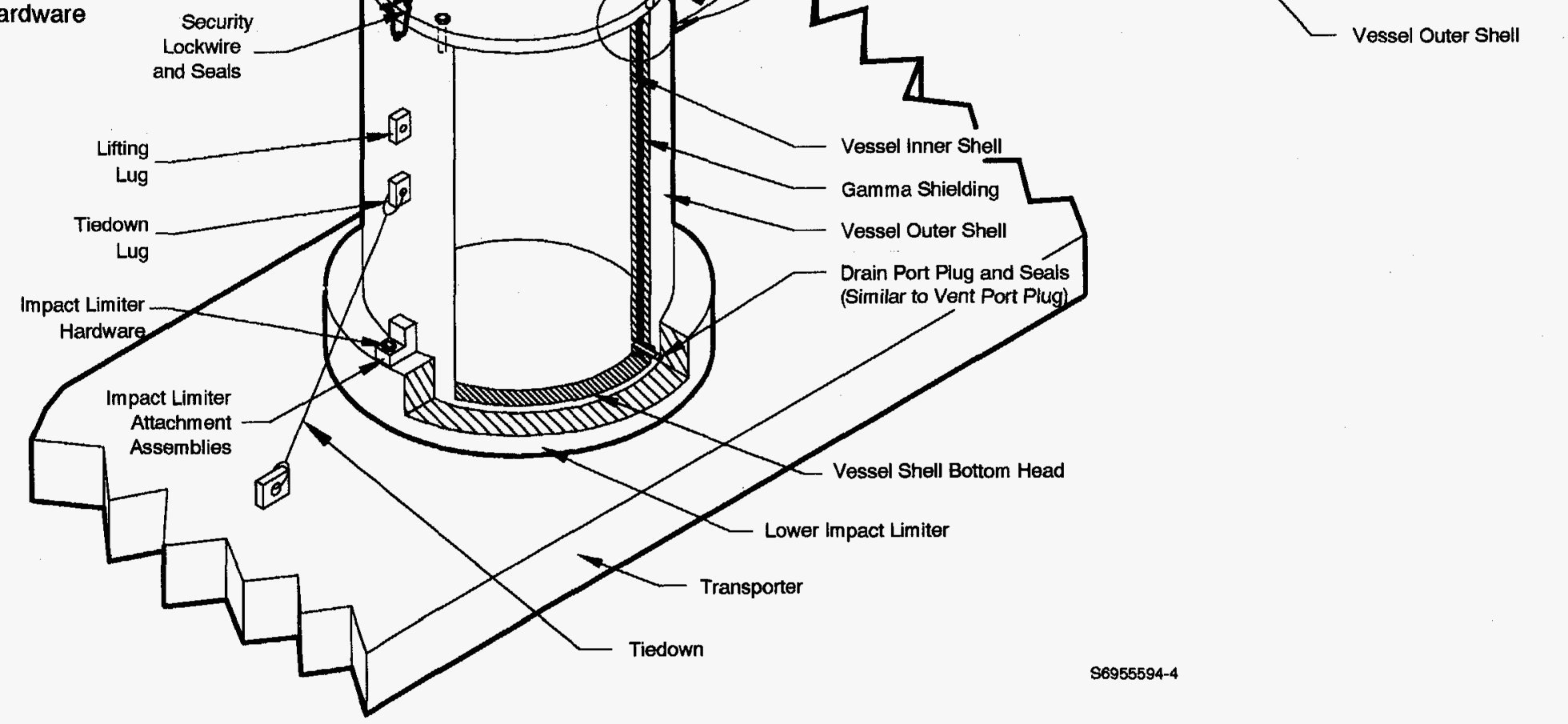

Figure 4. Schematic of a hypothetical Type B (Normal Form) activity packaging. 
pressure relief device are usually installed in the vessel lid. Lifting lugs, attachments, or threaded bolt holes are provided for rigging used to remove the lid from the packaging. A single failure of the vessel lid could either release radioactive material from the package or cause direct streaming of radiation to areas external to the packaging.

Vessel Lid Closure Hardware. Lids are assembled to the packaging with a number of bolts. The bolts are required for maintaining containment in the package under normal and accident conditions. The failure of a single closure bolt is not expected to release radioactive material to uncontrolled areas. However, if inferior bolts are installed, the containment may be breached during an accident condition. Therefore, the closure bolts are considered as a class to be prone to a single failure.

Vessel Lid Inner Seal. Two seals are usually provided on Type B (Normal Form) packaging Lids. The inner seal is required for maintaining containment in the package under normal and accident conditions. The outer seal is addressed under Category $\mathrm{C}$ items.

Vessel Shell Bottom Head. The vessel shell bottom head provides containment and often shielding for the lower end of the package under normal and accident conditions. The vessel shell bottom head may be welded to the vessel inner shell and the vessel outer shell. Shielding materials may extend to the vessel shell bottom head and in some packaging designs may be located inside the head. If so, the head may prevent draining of certain shield materials in the event of a post-accident fire. A single failure of this component could either release radioactive material from the package or, if shielding is lost, allow direct streaming of radiation to areas external to the packaging.

Vessel Shell Upper Head. The vessel shell upper head provides containment and shielding for the upper cylindrical end of the packaging. The head may have sealing surfaces for the package and bolt threads for closure of the package lid. The head is typically welded to the vessel inner shell and often to the vessel outer shell. Shielding materials may extend to the head. If so, the head may prevent draining of certain shield materials in a post-accident fire.

\subsubsection{Category B Items}

Drum. When used as an outer shell, the drum provides support for the contents in both normal and accident conditions. In order for the radioactive material to be released, both the outer drum and inner drum or container must be breached. That requires two failures.

Gamma Shielding. Gamma shielding is required to reduce external radiation doses to levels acceptable for transport. Lead, depleted uranium, and various steels have been used in the past for gamma radiation shielding. The presence and effectiveness of the shielding is subject to required testing during fabrication of the packaging. The shielding usually performs no other function than shielding, and its presence is sufficient to satisfy its function. The shielding is usually enclosed by the inner and outer shells and, as a solid, is not subject to removal during normal conditions of transport. Under many accident conditions, the shielding remains in place and still performs the intended function. However, some materials (e.g., lead) may melt in the event of a fire. Given that an analysis demonstrates that the expansion of the lead will not rupture the package containment, the molten material will remain in place unless the outer shell is breached. Therefore, two failures, loss of the outer shell and melting of the shielding, are required to prevent the shielding from performing its intended function. The requirements of a specific design may dictate that a higher category be assigned to gamma shielding in some circumstances.

Impact Limiter Hardware. Impact limiter hardware is used to attach the impact limiter to the rest of the packaging. The bolts keep the limiter in the configuration that will protect the packaging during any crushing that may occur in an accident. Due to redundancy, a failure of a portion of the bolts will not result in failure of the limiter to properly perform the intended function. If the redundancy argument is not applicable, the 
hardware should be Category A. The result could be failure of containment during an accident.

Leak Check Port PIug and Seal. The leak-tight characteristics of Type B (Normal Form) packaging are tested after manufacture or modification of the package and as part of the loading process. In this process, gas pressures are measured and samples are taken from between the inner and outer lid seals. Similar tests are performed on vent and outer seals. In all cases, a between-seals tap is made outside the inner seal that provides an initial level of containment. The plug and attendant seal are a second level of containment protection. Other considerations are that the plug may provide a shielding function in some packaging designs. Often, the port has a small diameter in a deep hole and is subject to columnation of the radiation.

Lifting Lugs, Trunnions, and Attachments. Type B (Normal Form) packages are usually lifted and attached to transportation skids through an attachment specifically designed for lifting. Lifting eyes, eye bolts, and installable assemblies are examples that might be used. Rigging and a hoist may be used to lift the packaging. Those attachments have a limited safety function during transportation. Failure of a properly designed attachment will not allow a breach of containment or criticality. The impact limiters would have to fail and either the containment boundary of the contents be breached or the contents supports be damaged to cause a significant failure.

The lifting attachments are also used inside facilities to lift the package from a transport skid and place the package into a loading station. For a facility, those steps may be a critical lift requiring a higher level of safety significance than would be found in transport. Quality inspection requirements, design loads in excess of transportation requirements, and post-load test inspectability are issues that may influence the category actually placed upon the lifting attachments.

Lifting/Tiedown Hardware. Sometimes, bolts are used in a lifting attachment. the bolts should have the same category as the lifting attachment. Like the lifting attachment, the bolts may have more rigorous quality requirements for use inside a facility than for transportation.

Tiedown Lugs. A transportation packaging is held to a vehicle with tiedowns and other similar devices. The packaging will often have attachments and lugs for connection of the tiedowns. The lugs are not necessary for containment, criticality control, or shielding in either normal or accident conditions.

Vessel Outer Shell. The vessel outer shell provides structural support for the Type B (Normal Form) package. The shell is typically welded to the vessel shell bottom head and the vessel shell upper head. The shell often is the outer wall of gamma shielding. The vessel outer shell usually is required to maintain configuration of the package in an accident condition. Many packaging designs provide features that mitigate the consequences of failure of the vessel outer shell. For example, breaching the vessel outer shell still requires a breach of the vessel inner shell before containment is breached, and impact limiters prevent vessel outer shell warpage that could open lid seals. Some packagings have gamma shielding that does not melt during the fire scenario. If the gamma shielding were able to melt and leak out through a vessel outer shell breach, then the shell should be a Category A item.

\subsubsection{Category C Items}

Dunnage. Dunnage is a packing material that is placed between the packaging and the contents to prevent movement of the contents during normal and sometimes accident transport conditions. Dunnage may be required to provide energy absorption and reduce the impact load. If the dunnage in a package is required to reduce impact loading on the containment boundary, it is a higher category item.

Packaging Hardware. Keepers are often used as a redundant feature to prevent bolts and nuts from becoming unscrewed, pins from falling out, and lifting attachments from being improperly used. Small bolts and nuts, cotter pins, detent 
pins, and lockwires have been used for this function. Lanyards are often used to attach bolts and keepers to the packaging to prevent misplacement of the parts. The keepers and lanyards usually do not have a direct safety implication and will not cause containment failure, loss of criticality control, or reduction of shielding capabilities if not present.

Protective Cover. Type B (Normal Form) packaging may have a protective cover and possibly some attachments. The cover serves to reduce accumulation of ice and dust from the surfaces of the package and has no safety function.

Security Lockwire and Seals. Security lockwire and seals are used in packaging to ensure that the contents shipped in the package are not tampered with. The function is a safeguard issue and not one of safety.

Skids/Forklift Channels. Sometimes, Type B (Normal Form) packaging has a shipping skid that may be equipped with channels for use with a forklift. Those assemblies have safety considerations that are similar to lifting attachments and shall have the same category as the lifting attachment. Sometimes, the skid or a portion of the skid is used as an impact limiter. It should be classed as Category $\mathrm{A}$ in those cases. Like the lifting attachment, the skid (including forklift channels) may have more rigorous quality requirements for use inside a facility than for transportation.

\section{Vent and Drain Port Plug and Pressure} Relief Device Outer Seals. The outer plug seals are used in testing the sealing capability of the inner seals and are not required for normal or accident conditions. If an outer seal leaks during testing, the test fails, requiring rework and retesting. Therefore, the outer seals may be of a lower category.

Vent, Drain, and Leak Check Port Plug Cover Plates. A cover plate is often placed over a vent, drain, or leak check port to control cleanliness in the ports and to provide protection from dirt and ice that may hamper receipt operations.

Vessel Lid Outer Seal. The outer lid seal is used in testing the sealing capability of the inner seal and is not required for normal or accident conditions. If the outer seal leaks during testing, the test fails, requiring rework and retesting. Therefore, the outer seal may be of a lower category item. 


\subsection{Packaging for Type B (Special Form) Shipments}

This section discusses considerations for assigning classification categories to components for a Type B (Special Form) packaging. This is a packaging designed to transport special form radioactive material that has a total activity greater than an $A_{1}$ quantity (e.g., radiography sources). Figures 5 and 6 depict two conceptual schematics of the components used in this type of packaging.

In most of the types of containers discussed in this report, the containment function will include control of direct radiation sources to prevent the release of airborne contamination. However, radioactive materials that have been classed as special form are sealed in such a way that contamination is not expected to be spread. Therefore, for Type B (Special Form) packaging, the containment function is required to retain the radioactive assembly inside a shielded area. Pressure-tight seals are not required for this function.

\subsubsection{Category A Items}

Impact Limiters. Impact Limiters are made up of a shell filled with energy-absorbing materials that limit mechanical damage in an accident. The function of the energy absorber is to crush during the accident. In crushing of the energy absorber, the impact limiter is performing its function, and crushing is not considered to be a failure of the material. Therefore, the properties of the materials used for energy absorption are important to the proper function of the impact limiter and to the safety of the package. Many different types of materials may be used as energy absorbers. In the past, plastic foams, metal honeycombs, and wood have been used. The shell is a metal skin that covers the energy-absorbing material and protects that material from minor damage and weather. In some cases, the shell may provide structural support to the impact limiter assembly. In such cases, the individual parts of the impact limiter assembly may have a lower classification category. Failure of the impact limiterwould result in a high potential for containment failure.

Temperature Control Components. Temperature control components may be required for packaging to withstand an accidental fire. Therefore, the packaging must prevent excessive heat from causing failure of the package under this extreme. Items such as fins, radiant heat shields, and insulation may be required to control temperature under accident conditions.

Vessel Inner Shell. The vessel inner shell provides containment and shielding for the body of the package under normal and accident conditions. The Type B (Special Form) packaging transports contents that have high external radiation and is provided with its own containment. Cladding of the radioactive source provides the primary level of containment.

Vessel Lid. The vessel lid provides containment and shielding for the upper end of the packaging. A single failure of this component could either release the radioactive source from the package or cause direct streaming of radiation to areas external to the packaging.

Vessel Lid Closure Hardware. Lids are assembled to the packaging with a number of bolts. The bolts are required for maintaining containment in the package under normal and accident conditions. The failure of a single closure bolt is not expected to release radioactive material to uncontrolled areas. However, if inferior bolts are installed, the containment may be breached during an accident condition. Therefore, the closure bolts are considered as a class to be prone to a single failure.

Special closure assemblies are often used in Type B (Special Form) packaging to provide containment of radioactive sources but allow safe use of the sources. Failure of an assembly may cause either release of the radioactive source from the package or cause direct streaming of radiation to areas external to the packaging. 

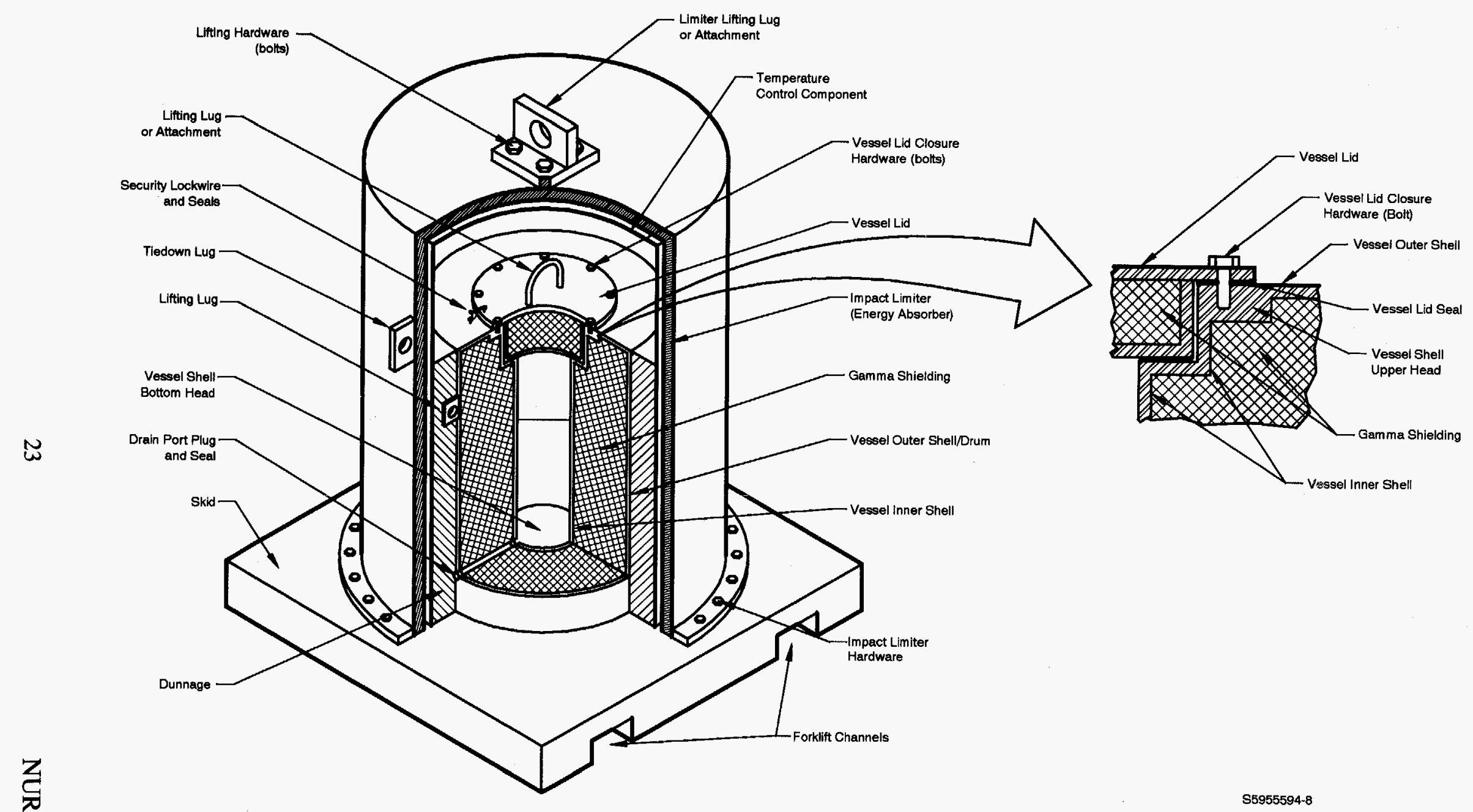

Figure 5. Schematic of a hypothetical Type B (Special Form) packaging. 
Transportation Packaging

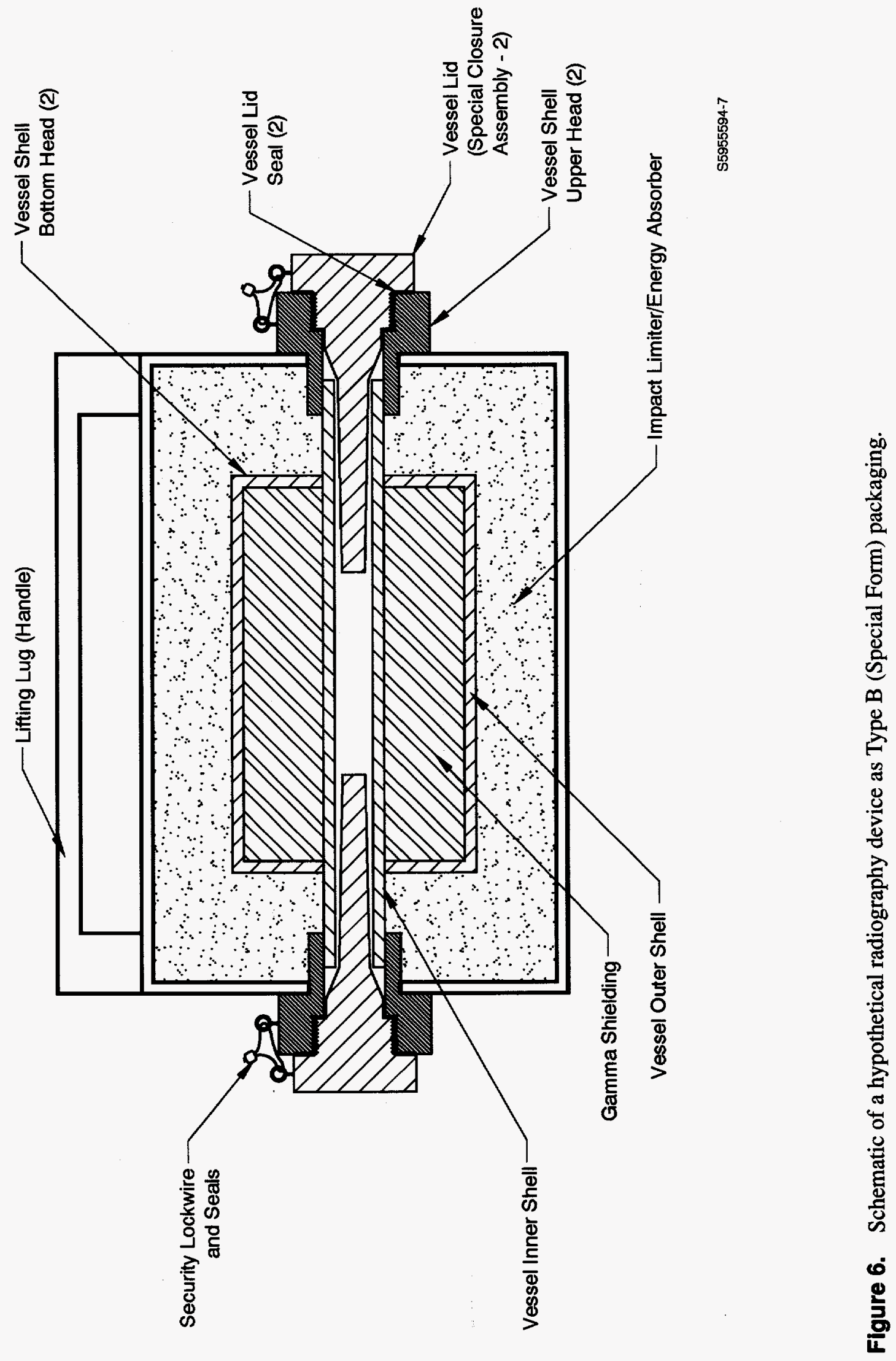


Vessel Shell Bottom Head. The vessel shell bottom head provides containment and often shielding for the lower end of the package under normal and accident conditions. A single failure of this component could either release the radioactive source from the package or, if shielding is lost, allow direct streaming of radiation to areas external to the packaging.

Vessel Shell Upper Head. The vessel shell upper head provides containment and shielding for the upper cylindrical end of the packaging. The head may have bolt threads for closure of the package lid. A single failure of this component could either release the radioactive source from the package or cause direct streaming of radiation to areas external to the packaging.

\subsubsection{Category B Items}

Drain Port Plug. In some applications, this type of packaging may be loaded under water. Drain ports are provided for removal of water from the packaging. A plug is provided to close each drain port. The plugs also are not required to maintain packaging containment under normal and accident conditions only if cladding of the contents fails.

Drum. When used as an outer shell, the drum provides support for the contents in both normal and accident conditions. In order for the radioactive material to be released, both outer drum and inner container must be breached. That requires two failures.

Gamma Shielding. Gamma Shielding is required to reduce external radiation doses to levels acceptable for transport. Lead, depleted uranium, and various steels have been used in the past for gamma radiation shielding. The presence and effectiveness of the shielding is subject to required testing during fabrication of the packaging. The shielding usually performs no other function than shielding and its presence is sufficient to satisfy its function. The shielding is usually enclosed by an outer shell and, as a solid, is not subject to removal during normal conditions of transport. Under many accident conditions, the shielding remains in place and still performs the intended function.
However, some materials (e.g., lead) may melt in the event of a fire. If an analysis demonstrates that the expansion of the lead will not rupture the package containment, the molten material will remain in place unless the shielding skin is breached. The melting of lead also requires the failure of the temperature control components of the packaging. Therefore, two failures, loss of the outer shell and melting of the shielding, are required to prevent the shielding from performing its intended function. The requirements of a specific design may dictate that a higher category be assigned to gamma shielding in some circumstances.

Impact Limiter Hardware. Impact limiter hardware is used to attach the impact limiter to the rest of the packaging. The bolts keep the limiter in the configuration that will protect the packaging during any crushing that may occur in an accident. Due to redundancy, the failure of a portion of the bolts will not result in failure of the limiter to properly perform the intended function. If the redundancy argument is not applicable, the hardware should be Category $A$. The result could be failure of containment and shielding during an accident.

Lifting Lugs, Trunnions, and Attachments. Type B (Special Form) packages are usually lifted through an attachment specifically designed for lifting. Lifting eyes, eye bolts, and installable assemblies are examples that might be used. Rigging and a hoist may be used to lift the packaging. Those attachments have a limited safety function during transportation. Failure of a properly designed attachment will not allow a breach of containment. The impact limiters would have to fail and the containment boundary of the contents be breached to cause a significant failure.

The lifting attachments are also used inside facilities to lift the package from a transport skid and place the package into a loading station. For a facility, those steps may be a critical lift requiring a higher level of safety significance than would be found in transport. Quality inspection requirements, design loads in excess of transportation requirements, and post-load test inspectability are issues that may influence the category actually placed upon the lifting attachments. 
Lifting/Tiedown Hardware. Sometimes, bolts are used in a lifting attachment. the bolts should have the same category as the lifting attachment. Like the lifting attachment, the bolts may have more rigorous quality requirements for use inside a facility than for transportation.

Tiedown Lugs. A transportation packaging is held to a vehicle with tiedowns and other similar devices. The packaging will often have attachments and lugs for connection of the tiedowns. The lugs are not necessary for containment, criticality control, or shielding in either normal or accident conditions.

Vent and Drain Port Plug and Pressure Relief Device Seals. Seals are usually provided for each vent and drain port plug and pressure relief device. Seals of the packaging are required only if cladding of the contents fails. This is a secondary failure.

Vessel Lid Seal. Materials transported in a Type B (Special Form) package are usually sealed radioactive sources that have some form of cladding to provide containment. Seals of the packaging are required only if the source cladding fails. This is a secondary failure.

Vessel Outer Shell. The vessel outer shell provides protection for the shielding from damage incidental to normal and accident conditions. Therefore, the shell has a secondary function and is a Category B item. However, the shell may be required to contain molten shielding in some packagings. Under those conditions, the shell is a Category A item.

\subsubsection{Category C Items}

Dunnage. Dunnage is a packing material that is placed between the packaging and the contents to prevent movement of the contents during normal and sometimes accident transport conditions. Dunnage is required to provide energy absorption and reduce the impact load. If Dunnage in a package is required to reduce impact loading on the containment boundary, the dunnage is a higher category item.

Packaging Hardware. Keepers are often used as a redundant feature to prevent bolts and nuts from becoming unscrewed, pins from falling out, and lifting attachments from being improperly used. Small bolts and nuts, cotter pins, detent pins, and lockwires have been used for this function. Lanyards are often used to attach bolts and keepers to the packaging to prevent misplacement of the parts. The keepers and lanyards usually do not have a direct safety implication and will not cause containment failure, loss of criticality control, or reduction of shielding capabilities if not present.

Security Lockwire and Seals. Security lockwire and seals are used in packaging to ensure that the contents shipped in the package are not tampered with. The function is a safeguard issue and not one of safety.

Skids/Forklift Channels. Sometimes, Type B (Special Form) packaging has a shipping skid that may be equipped with channels for use with a forklift. Those assemblies have safety considerations that are similar to lifting attachments and shall have the same category as the lifting attachment. Sometimes, the skid or a portion of the skid is used as an impact limiter. It should be classed as Category $\mathrm{A}$ in those cases. Like the lifting attachment, the a skid (including forklift channels) may have more rigorous quality requirements for use inside a facility than for transportation. 


\subsection{Packaging for Type B (Fissile) Shipments}

This section discusses considerations for assigning classification categories to components for a Type B (Fissile) packaging. This is a packaging designed to transport fissile material that does not meet the fissile material exemption standards in 10 CFR $71.53^{1}$ and has a total radioactivity greater than an $A_{1}$ or an $A_{2}$ quantity (e.g., irradiated nuclear reactor fuel). Figure 7 depicts a conceptual schematic of the components used in this type of packaging.

\subsubsection{Category A Items}

Contents Support Structure. The contents supports provide mechanical support for the fissile contents of the package. The structure is required to maintain spacing between content assemblies, support neutron absorbers, and prevent content movement into configurations that have not been analyzed for nuclear criticality. The structure must function as a single assembly under normal and accident conditions.

Drain Port Plug. Most Type B (Fissile) packaging is loaded under water. Drain ports are provided for removal of water from the packaging. A plug is provided to close each drain port. The plugs also are required to maintain packaging containment under normal and accident conditions.

Impact Limiters. Impact limiters are made up of a shell filled with energy-absorbing materials that limit mechanical damage in an accident. The function of the energy absorber is to crush during the accident. In crushing of the energy absorber, the impact limiter is performing its function, and crushing is not considered to be a failure of the material. Therefore, the properties of the materials used for energy absorption are important to the proper function of the impact limiter and to the safety of the package. Many different types of materials may be used as energy absorbers. In the past, plastic foams, metal honeycombs, and wood have been used. The shell is a metal skin that covers the energy-absorbing mate- rial and protects that material from minor damage and weather. In some cases, the shell may provide structural support to the impact limiter assembly. In such cases, the individual parts of the impact limiter assembly may have a lower category level. Failure of the impact limiter may result in failures of containment and criticality control due to structural damage of those components.

Neutron Absorbers. Neutron absorbers are often used for control of criticality in Type B (Fissile) packaging. In other packages, castable neutron absorbers may be used. The absorber material is required for criticality control under normal and accident conditions.

Pressure Relief Device. Pressure relief devices are used to limit the internal pressure of Type B (Fissile) packaging. Those devices could include rupture disks or pressure relief valves. In addition, those devices also are required to maintain packaging containment under normal and accident conditions.

Temperature Control Components. Temperature control components are required for two conditions. The packaging is required to withstand an accidental fire. Therefore, the packaging must prevent excessive heat from causing failure of the package under this extreme. Conversely, the contents of a Type B (Fissile) produces a significant amount of heat. That heat must be removed from the package. Items such as fins, radiant heat shields, and insulation are required to control temperature under normal and accident conditions.

Vent and Drain Port Plug and Pressure Relief Device Inner Seals. Two seals are usually provided for each vent and drain port plug and pressure relief device. The inner seals are required for maintaining containment in the package under normal and accident conditions. The outer seals are addressed under Category $\mathrm{C}$ items.

Vent Port Plug. Many Type B (Fissile) packagings are equipped with a vent port. The port may be used for transferring gas into and out of the packages during filling with water. Gas may 


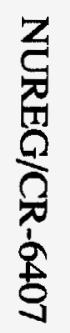

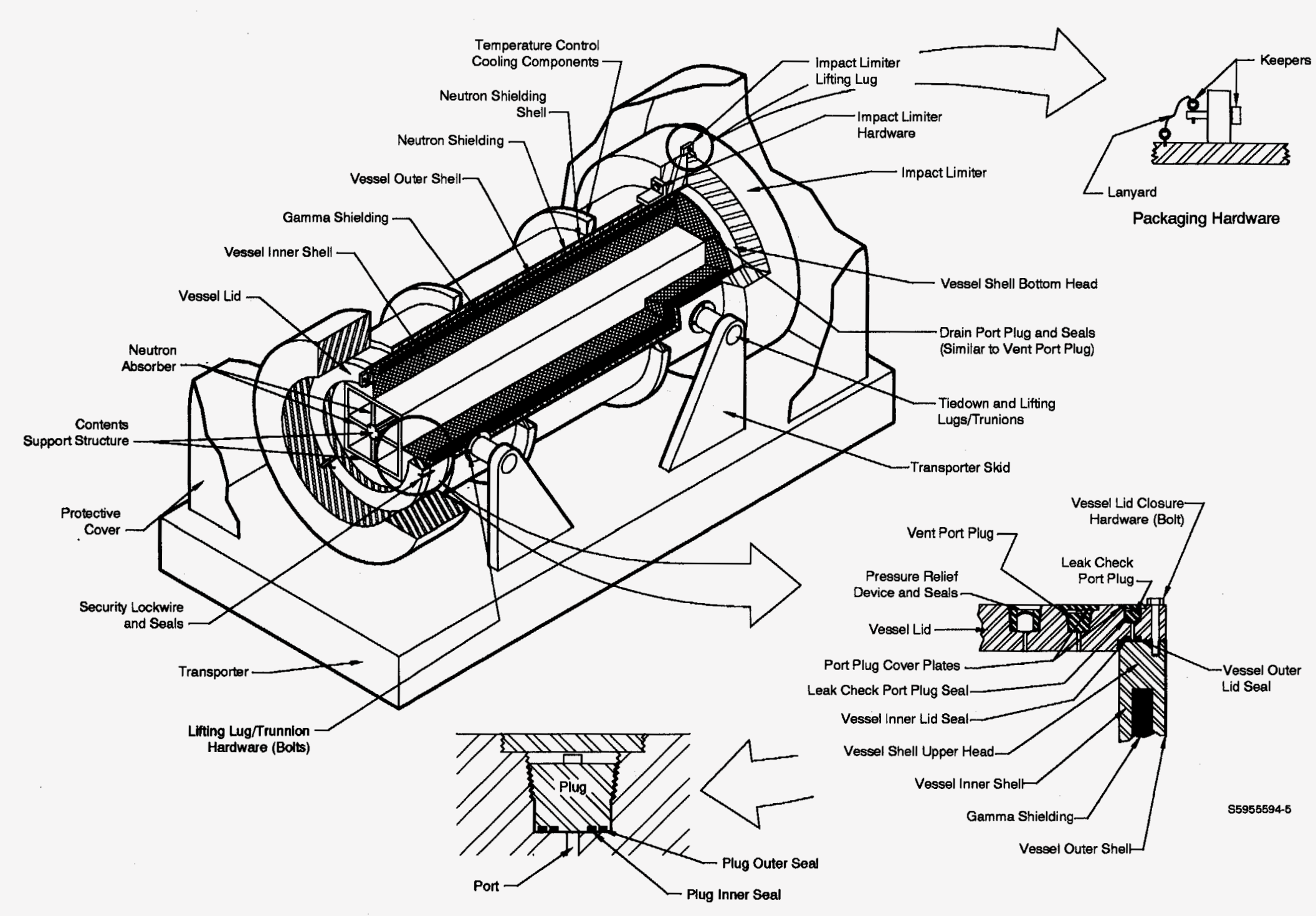

Figure 7. Schematic of a hypothetical Type B (Fissile) packaging. 
be purged through the port for control of gas carried contamination, radioactive gases, or gases generated by the contents of the package. Some packagings require the displacement of interior gas to remove or install the lid. A plug is provided to close the vent during transport. The plug is required to maintain packaging containment under normal and accident conditions.

Vessel Inner Shell. The vessel inner shell is the interior wall of the packaging and is typically welded to the vessel shell bottom head and the vessel shell upper head. The vessel inner shell is part of the containment under normal and accident conditions. A single failure could release radioactive material outside the packaging.

Vessel Lid. The vessel lid provides containment and often shielding for the upper end of the packaging under normal and accident conditions. The vessel lid will have closure bolt holes and sealing surfaces. Vent port, leak check port, and a pressure relief device are usually installed in the lid. Attachments or threaded bolt holes are provided for rigging used to remove the lid from the packaging. A single failure of the vessel lid could either release radioactive material from the package or cause direct streaming of radiation to areas external to the packaging.

Vessel Lid Closure Hardware. Lids are assembled to the packaging with a number of bolts. The bolts are required for maintaining containment in the package under normal and accident conditions. The failure of a single closure bolt is not expected to release radioactive material to uncontrolled areas. However, if inferior bolts are installed, the containment may be breached during an accident condition. Therefore, the closure bolts are considered as a class to be prone to a single failure.

Vessel Lid Inner Seal. Two seals are usually provided on Type B (Fissile) packaging lids. The inner seal is required for maintaining containment in the package under normal and accident conditions. The outer seal is addressed under Category $\mathrm{C}$ items.
Vessel Shell Bottom Head. The vessel shell bottom head provides containment and often shielding for the lower end of the package under normal and accident conditions. The vessel shell bottom head may be welded to the vessel inner shell and the vessel outer shell. Shielding materials may extend to the vessel shell bottom head and in some packaging designs may be located inside the head. If so, the head may prevent draining of certain shield materials in the event of a post-accident fire. A single failure of this component would either release radioactive material from the package or, if shielding is lost, allow direct streaming of radiation to areas external to the packaging.

Vessel Shell Upper Head. The vessel shell upper head provides containment and shielding for the upper cylindrical end of the packaging. The head may have sealing surfaces for the package and bolt threads for closure of the package lid. The head is typically welded to the vessel inner shell and often to the vessel outer shell. Shielding materials may extend to the head. If so, the head may prevent draining of certain shield materials in a post-accident fire.

\subsubsection{Category B Items}

Drum. When used as an outer shell, a drum provides support for the contents in both normal and accident conditions. In order for the radioactive material to be released, both outer drum and inner drum or container must be breached. That requires two failures.

Gamma Shielding. Gamma shielding is required to reduce external radiation doses to levels acceptable for transport. Lead, depleted uranium, and various steels have been used have been used in the past for gamma radiation shielding. The presence and effectiveness of the shielding is subject to required testing during fabrication of the packaging. The shielding usually performs no other function than shielding and its presence is sufficient to satisfy its function. The shielding is usually enclosed by the inner and outer shells and, as a solid, is not subject to removal during normal conditions of transport. Under many accident conditions, the shielding 
remains in place and still performs the intended function. However, some materials (e.g., lead) may melt in the event of a fire. Given that an analysis demonstrates that the expansion of the lead will not rupture the package containment, the molten material will remain in place unless the outer shell is breached. Therefore, two failures, loss of the outer shell and melting of the shielding, are required to prevent the shielding from performing its intended function. The requirements of a specific design may dictate that a higher category be assigned to gamma shielding.

Impact Limiter Hardware. Impact limiter hardware is used to attach the impact limiter to the rest of the packaging. The bolts keep the limiter in the configuration that will protect the packaging during any crushing that may occur in an accident. Due to redundancy, a failure of a portion of the bolts will not result in failure of the limiter to properly perform the intended function. If the redundancy argument is not applicable, the hardware should be Category $\mathrm{A}$. The result could be failure of containment and criticality control during an accident.

Leak Check Port Plug and Seal. The leak-tight characteristics of Type B (Fissile) packaging are tested after manufacture or modification of the package and as part of the loading process. In this process, gas pressures and samples are taken from between the inner and outer lid seals. Similar tests are performed on vent and outer seals. In all cases, a between-seals tap is made outside the inner seal that provide an initial level of containment. The plug and attendant seal are a second level of containment protection. Other considerations are that the plug may provide a shielding function in some packaging designs. Often, the port has a small diameter in a deep hole and is subject to columnation of the radiation.

Lifting Lugs, Trunnions, and Attachments. Type B (Fissile) packagings are usually lifted and attached to transportation skids through trunnions. The trunnions are attached to the packaging but have a limited safety function during transportation. Failure of a properly designed single trunnion will not allow a breach of containment or criticality. Failure of all trunnions could cause the package to leave the transportation skid. However, the impact limiters would also have to fail and either the containment boundary be breached or the contents supports be damaged to cause a significant failure.

The trunnions are also used inside facilities to lift the package from a transport skid and place the package into a loading station. For a facility, those steps may be a critical lift requiring a higher level of safety significance than would be found in transport. Quality inspection requirements, design loads in excess of transportation requirements, and post-load test inspectability are issues that may influence the category actually placed upon the trunnions.

Similar classifications would apply if lifting lugs or other attachments are used for tiedown and lifting Type $\mathrm{B}$ (Fissile) packaging.

Lifting/Tiedown Hardware. Sometimes, bolts are used to attach trunnions to a Type B (Fissile) package. The bolts should have the same category as the trunnion. Like the trunnions, the bolts may have more rigorous quality requirements for use inside a facility than for transportation.

Neutron Shielding. Shielding is often provided to reduce the neutron dose external to the package. The design usually dictates that the neutron shielding be placed external to the gamma shielding and the vessel outer shell. The materials of construction are often light weight hydrocarbon materials with a high hydrogen content. This type of material typically has a low melting point that may be lost in the event of an accidental fire. It is common practice to design packaging so that neutron shielding is required for normal conditions but not required for the accident condition. Under an accident condition, the radiation dose is allowed to raise to above levels required for normal transport. 
Neutron Shielding Shell. A thin skin of metal may be used to cover neutron shielding during normal transport. The skin allows for decontamination of the package after underwater loading, prevents deterioration of shielding due to weather, and protects the shielding from minor damage incidental to transport. Temperature control devices such as fins may protrude through the skin. The skin is usually thin compared with structural components and, therefore, has negligible effect on any containment and on criticality.

Tiedown Lugs. A transportation packaging is held to a transportation skid or vehicle with tiedowns and other similar devices. The packaging will often have attachments and lugs for connection of the tiedowns. The lugs are not necessary for containment, criticality control, or shielding in either normal or accident conditions.

Vessel Outer Shell. The vessel outer shell provides structural support for the Type B (Fissile) package. The shell is typically welded to the vessel shell bottom head and the vessel shell upper head. The shell often is the outer wall of gamma shielding and sometimes is the inner wall for neutron shielding. Temperature control components such as fins are often attached to the vessel outer shell. The vessel outer shell usually is required to maintain configuration of the package in an accident condition. Many packaging designs provide features that mitigate the consequences of failure of the vessel outer shell. For example, breaching the vessel outer shell still requires a breach of the vessel inner shell before containment is breached, and impact limiters prevent vessel outer shell warpage that could open lid seals. Some packagings have gamma shielding that does not melt during the fire scenario. If the gamma shielding were to melt and leak out through a vessel outer shell breach, then the shell should be a higher category item.

\subsubsection{Category C Items}

Dunnage. Dunnage is a packing material that is placed between the packaging and the contents to prevent movement of the contents during normal and sometimes accident transport conditions. Dunnage is required to provide energy absorption and reduce the impact load. If Dunnage in a package is required to reduce impact loading on the containment boundary, the dunnage is a higher category item.

Packaging Hardware. Keepers are often used as a redundant feature to prevent bolts and nuts from becoming unscrewed, pins from falling out, and lifting attachments from being improperly used. Small bolts and nuts, cotter pins, detent pins, and lockwires have been used for this function. Lanyards are often used to attach bolts and keepers to the packaging to prevent misplacement of the parts. The keepers and lanyards usually do not have a direct safety implication and will not cause containment failure, loss of criticality control, or reduction of shielding capabilities if not present.

Protective Cover. Type B (Fissile) packaging will often have a protective cover and possibly some attachments. The cover serves to reduce accumulation of ice and dust from the surfaces of the package and has no safety function.

Security Lockwire and Seals. Security lockwire and seals are used in packaging to ensure that the contents shipped in the package are not tampered with. The function is a safeguard issue and not one of safety.

Skids/Forklift Channels. Sometimes, Type B (Fissile) packaging has a shipping skid that may be equipped with channels for use with a forklift. Those assemblies have safety considerations that are similar to lifting attachments and shall have the same category as the lifting attachment. Sometimes, the skid or a portion of the skid is used as an impact limiter. It should be classed as Category $\mathrm{A}$ in those cases. Like the lifting attachment, the skid (including forklift channels) may have more rigorous quality requirements for use inside a facility than for transportation.

Vent and Drain Port Plug and Pressure Relief Device Outer Seals. The plug outer seals are used in testing the sealing capability of the inner seals and are not required for normal or accident conditions. If an outer seal leaks during testing, the test fails, requiring rework and 
retesting. Therefore, the outer seals may be a lower category item.

Vent, Drain, and Leak Check Port Plug Cover Plates. A cover plate is often placed over a vent, drain, or leak check port to control cleanliness in the ports and to provide protection from dirt and ice that may hamper receipt operations.
Vessel Lid Outer Seal. The lid outer seal is used in testing the sealing capability of the inner seal and is not required for normal or accident conditions. If the outer seal leaks during testing, the test fails, requiring rework and retesting. Therefore, the outer seal may be a lower category item. 
Table 5. Classification categories for Transportation Packaging Categories I, II, and III components.

\begin{tabular}{|c|c|c|c|c|c|c|}
\hline \multirow[b]{4}{*}{ Function } & \multirow[b]{4}{*}{ Component } & \multicolumn{5}{|c|}{ Packaging Category III } \\
\hline & & \multirow[b]{3}{*}{$\begin{array}{c}\text { Type A } \\
\text { (Fissile) }\end{array}$} & \multicolumn{4}{|c|}{ Packaging Category II } \\
\hline & & & \multirow[b]{2}{*}{ LSA } & \multicolumn{3}{|c|}{ Packaging Category I } \\
\hline & & & & $\begin{array}{c}\text { Type B } \\
\text { (Normal } \\
\text { Form) }\end{array}$ & $\begin{array}{c}\text { Type B } \\
\text { (Special } \\
\text { Form) }\end{array}$ & $\begin{array}{l}\text { Type B } \\
\text { (Fissile) }\end{array}$ \\
\hline \multirow[t]{13}{*}{ Containment $^{\mathrm{a}}$} & Drain port plug & - & B & A & $\mathbf{B}$ & A \\
\hline & Leak check port plug and seal & - & - & $\mathrm{B}$ & - & B \\
\hline & Pressure relief device & - & B & A & - & A \\
\hline & $\begin{array}{l}\text { Vent and drain port plug and pressure relief } \\
\text { device inner seals }\end{array}$ & - & - & A & - & A \\
\hline & $\begin{array}{l}\text { Vent and drain port plug and pressure relief } \\
\text { device seals }\end{array}$ & - & B & - & $\mathbf{B}$ & - \\
\hline & Vent port plug & - & B & A & - & A \\
\hline & Vessel inner shell & $\mathbf{B}$ & B & A & A & A \\
\hline & Vessel lid & B & B & A & A & A \\
\hline & Vessel lid closure hardware & $\mathbf{B}$ & B & A & A & $\mathrm{A}$ \\
\hline & Vessel lid inner seal & - & - & A & 一 & A \\
\hline & Vessel lid seal & $\mathbf{B}$ & B & - & B & - \\
\hline & Vessel shell bottom head & - & B & A & A & A \\
\hline & Vessel shell upper head & - & B & A & A & A \\
\hline \multirow[t]{2}{*}{ Criticality control } & Contents support structure & A & - & - & 一 & A \\
\hline & Neutron absorbers & A & - & - & - & A \\
\hline \multirow[t]{2}{*}{ Shielding } & Gamma shielding & 一 & $\mathrm{B}^{\mathrm{b}}$ & $\mathbf{B}^{\mathbf{b}}$ & $\mathbf{B}^{\mathbf{b}}$ & $\mathrm{B}^{\mathbf{b}}$ \\
\hline & Neutron shielding & - & - & - & - & $\mathrm{B}^{\mathbf{b}}$ \\
\hline Heat transfer & Temperature control components & - & - & A & A & A \\
\hline \multirow[t]{6}{*}{ Structural integrity ${ }^{\mathrm{c}}$} & Drum & B & $\mathbf{B}$ & $\mathrm{B}$ & $\mathbf{B}$ & $\mathbf{B}$ \\
\hline & Dunnage & $C^{d}$ & $C^{d}$ & $\mathrm{C}^{\mathrm{d}}$ & $C^{d}$ & $\mathrm{C}^{\mathrm{d}}$ \\
\hline & Impact limiters ${ }^{\mathrm{e}}$ & A & - & A & A & A \\
\hline & Impact limiter hardware & - & - & B & $\mathbf{B}$ & B \\
\hline & Packaging hardware & $\mathrm{C}$ & $\mathrm{C}$ & C & $\mathrm{C}$ & $\mathrm{C}$ \\
\hline & Vessel outer shell & B & $\mathbf{B}^{\mathrm{f}}$ & $B^{f}$ & $\mathbf{B}^{\mathbf{f}}$ & $B^{f}$ \\
\hline \multirow[t]{10}{*}{ Operations support } & Lifting lugs, trunnions, and attachments & B & B & B & B & B \\
\hline & Lifting/tiedown hardware & B & $\mathbf{B}$ & B & B & B \\
\hline & Neutron shielding shell & - & - & - & - & B \\
\hline & Protective cover & - & $\mathrm{C}$ & $\mathrm{C}$ & - & $\mathrm{C}$ \\
\hline & Security lockwire and seals & $\mathrm{C}$ & C & $\mathrm{C}$ & $\mathrm{C}$ & $\mathrm{C}$ \\
\hline & Skids/forklift channels & $\mathrm{C}$ & $\mathrm{C}$ & $\mathrm{C}^{\mathrm{e}}$ & $\mathrm{C}^{\mathrm{e}}$ & $\mathbf{C}^{\mathrm{e}}$ \\
\hline & Tiedown lugs & - & B & B & $\mathbf{B}$ & B \\
\hline & $\begin{array}{l}\text { Vent and drain port plug and pressure relief } \\
\text { device outer seals }\end{array}$ & - & - & $\mathrm{C}$ & - & C \\
\hline & $\begin{array}{l}\text { Vent, drain, and leak check port plug cover } \\
\text { plates }\end{array}$ & - & - & $\mathrm{C}$ & - & $\mathrm{C}$ \\
\hline & Vessel lid outer seal & - & 一 & $\mathbf{C}$ & - & $\mathbf{C}$ \\
\hline \multicolumn{7}{|c|}{$\begin{array}{l}\text { a. Containment boundary of the package is defined by the components incorporated in the container design for the purpose of retaining the } \\
\text { radioactive material during normal and accident conditions. }\end{array}$} \\
\hline \multicolumn{7}{|c|}{ b. Shielding may be Category A for some designs. } \\
\hline \multirow{2}{*}{\multicolumn{7}{|c|}{$\begin{array}{l}\text { c. Required to maintain structural integrity and configuration in either normal or accident conditions. } \\
\text { d. Dunnage may be a Category B item if required for limiting impact in an accident. }\end{array}$}} \\
\hline & & & & & & \\
\hline \multicolumn{7}{|c|}{ e. If the skid or a portion of the skid is used as an impact limiter, it should be classed as Category A. } \\
\hline
\end{tabular}




\section{DRY SPENT FUEL STORAGE SYSTEMS}

This section provides detailed descriptions of the components that make up the two dry spent fuel storage systems: the metal shielded type and the concrete shielded type. Table 6 (located at the end of this section) presents the classification categories for those storage systems. Vendor assignment of classifications that are different from those in the table is acceptable but must be justified as discussed in Section 3.

\subsection{Metal Shielded Type Storage Systems}

This section discusses considerations for assigning classification categories to components for a metal shielded type system for storage of spent fuel. Figure 8 depicts a conceptual schematic of a vertical metal shielded storage system with typical components used in this type of system, while Table 6 lists the categories assigned. This type of system may be constructed in a horizontal configuration also. One method of storage in the metal shielded type of storage system is to employ an integral shielded storage cask. In this type of system, the shielded cask may be loaded and sealed in a facility. The loaded and sealed cask is then moved to the storage location. In other versions of this system, an inner cask may be loaded in a facility, then placed in a transfer cask and moved to the outer storage cask. The inner cask is then placed in the outer storage cask. Various designs of this type have been tested and used in the past.

Another variation on this type of storage system is to use a shielded outer cask that contains an inner cask. Spent fuel is loaded into the inner cask inside a facility. That cask is then moved to the shielded outer cask in a shielded transfer cask. The inner cask may then be transferred into the shielded outer cask for storage.

\subsubsection{Category A Items}

Basket Assembly. The basket assembly provides mechanical support for the fissile con- tents of the storage system. The structure is required to maintain spacing between content assemblies, and support neutron absorbers, and prevent content movement into configurations that have not been analyzed for nuclear criticality. The structure must function under normal and accident conditions.

Drain Port Plug. Most inner casks and containment type storage casks are loaded under water. Drain ports are provided for removal of water from the casks. A plug is provided to close each drain port. The plug is also required to maintain containment under normal and accident conditions.

Inner Cask Bottom Head. The inner cask bottom head provides containment for the lower end of the cask under normal and accident conditions. The bottom head is welded to the inner cask shell. A single failure of this component could release radioactive material from the inner cask.

Inner Cask Lid. The inner cask lid provides containment for the upper end of the cask under normal and accident conditions. The lid will have closure bolt holes and sealing surfaces. Vent port, leak check port, and a pressure relief device are usually installed in the lid. Attachments or threaded bolt holes are provided for rigging used to remotely handle the inner cask and remove the lid from the cask. A single failure of the lid could release radioactive material from the inner cask.

Inner Cask Lid Seals. Seals are usually used on containment lids. The seals are required for maintaining containment in the inner cask under normal and accident conditions.

Inner Cask Shell. The inner cask shell is the cylindrical wall of the removable inner cask that contains the spent fuel. The shell is typically welded to the inner cask bottom head and the inner cask shell upper head. The inner cask shell is part of the containment under normal and accident conditions. A single failure could release radioactive material outside the system. 
Dry Spent Fuel Storage Systems

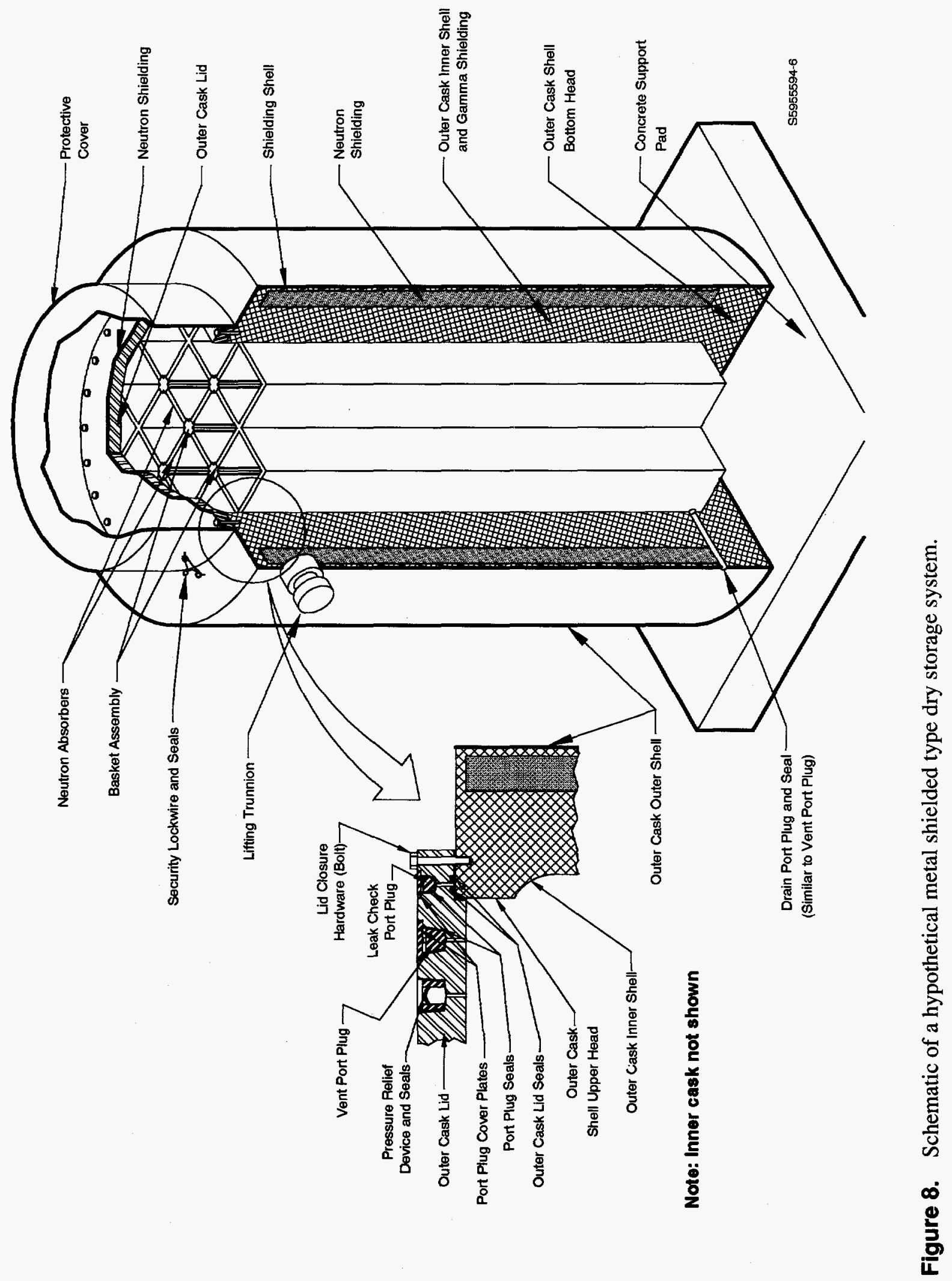


Inner Cask Shell Upper Head. The inner cask shell upper head provides containment for the upper cylindrical end of the cask. The head may have sealing surfaces for the inner cask and bolt threads for closure of the inner cask lid. The head is typically welded to the inner cask shell.

Leak Check Port Plug. The leak-tight characteristics of inner cask or containment-type outer storage casks are tested after manufacture and as part of the loading process. In this process, gas pressures are measured and samples are taken from between the two lid seals. Similar tests are performed between inner and outer seals. In all cases, a between-seals tap is made outside the inner seal. The inner seal provides an initial level of containment. The plug and attendant seal are a second level of containment protection. Other considerations are that the plug may provide a shielding function in some cask designs. Often times, the port has a small diameter in a deep hole and is subject to columnation of the radiation.

Lid Closure Hardware. Some lids are assembled to either the inner cask or the containment type outer cask with a number of bolts. The bolts are required for maintaining containment in the cask under normal and accident conditions. The failure of a single bolt is not expected to release radioactive material to uncontrolled areas. However, if inferior bolts are installed, the containment may be breached during an accident condition. Therefore, the bolts are considered as a class to be prone to a single failure.

Bolts may also be used for closing a shieldingtype outer cask. Those bolts are of a secondary function and may be considered to be Category B components.

Lifting Lugs/Trunnions/Grapples. Some dry spent fuel storage systems may be provided with lifting lugs for handling inside a facility. Containment type outer storage casks are usually lifted through trunnions. Failure of a properly designed lifting lug or trunnion may result in dropping an outer cask, dropping an inner cask while in a shielded area, or an inner cask within a transfer device. Those accidents could result in a breach of containment or criticality. Direct radiation effects are limited to levels allowed under accident conditions. Damage could be imposed on the facility as well. The movement of nuclear fuel in a facility is a critical lift requiring a high level of safety.

Lifting Lug/Trunnion Bolts. Sometimes, bolts are used to attach trunnions to a dry spent fuel storage system. The bolts should have the same category as the trunnion.

Neutron Absorbers. Neutron absorbers may be used for control of criticality in many dry spent fuel storage systems. Castable absorbers may be used in other systems. The absorber material is required for criticality control under normal and accident conditions.

Outer Cask Inner Shell. The outer cask inner shell is the interior wall of the cask and is typically welded to the cask bottom head and the cask shell upper head. In some metal shielded type systems, the outer cask provides containment for the radioactive contents of the cask. In those systems, the outer cask inner shell is part of the containment under normal and accident conditions. A single failure could release radioactive material outside the cask.

In systems that use an inner cask for containment, the outer cask provides only shielding. The outer cask inner shell provides support for the shielding and therefore has a secondary safety role. In that case, the outer cask inner shell, may be considered to be a Category $B$ item.

Outer Cask Lid. For systems where the cask provides containment, the cask lid is a primary barrier to the release of radioactive material. The lid provides containment and often shielding for the upper end of the cask under normal and accident conditions. The lid will have closure bolt holes and sealing surfaces. A vent port, leak check port, and a pressure relief device are usually installed in the lid. Attachments or threaded bolt holes are provided for rigging used to remove the lid from the cask. A single failure of the lid could either release radioactive material from the package or cause direct streaming of radiation to areas external to the cask. 
In systems that use an inner cask for containment, the outer cask provides only shielding. The outer cask lid provides support for the shielding and therefore has a secondary safety role. In that case, the outer cask lid may be considered to be a Category B item.

Outer Cask Lid Seals. Seals are usually used on containment lids. The seals are required for maintaining containment in the cask under normal and accident conditions. Depending on the design, the outer seal may be a lower category item.

Outer Cask Shell Bottom Head. For systems where the outer cask provides containment, the outer cask shell bottom head is a primary barrier to the release of radioactive material. The head provides containment and often shielding for the lower end of the cask under normal and accident conditions. The bottom head may be welded to the inner shell and the outer shell. Shielding materials may extend to the bottom head and in some cask designs may be located inside the head. If so, the head may prevent draining of certain shield materials in the event of a post-accident fire. A single failure of this component could either release radioactive material from the cask, or if shielding is lost, allow direct streaming of radiation to areas external to the cask.

In systems that use an inner cask for containment, the outer cask provides only shielding. The outer cask bottom head provides support for the shielding and therefore has a secondary safety role. In that case, the cask bottom head may be considered to be a Category B item.

Outer Cask Shell Upper Head. For systems where the cask provides containment, the outer cask shell upper head is a primary barrier to the release of radioactive material. The head provides containment and shielding for the upper cylindrical end of the cask. The head may have sealing surfaces for the cask and lid bolt holes threads for closure of the cask lid. The head is typically welded to the outer cask inner shell and often to the outer shell. Shielding materials may extend to the head. If so, the head may prevent draining of certain shield materials in the event of a post-accident fire.

In systems that use an inner cask for containment, the outer cask provides only shielding. The outer cask shell upper head provides support for the shielding, and therefore, has a secondary safety role. In that case, the outer cask shell upper head may be considered to be a Category B item.

Pressure Relief Device. Pressure relief devices are used to limit the internal pressure within the containment boundary. Pressure relief devices could include rupture disks or pressure relief valves. In addition, those devices also are required to maintain containment under normal and accident conditions.

Temperature Control Components. Temperature control components are required for two conditions. Spent fuel produces a significant amount of decay heat that must be removed from the storage system. Conversely, the storage system is required to withstand an accidental fire. Therefore, the system must prevent excessive heat from causing failure of the cask under this extreme condition. Items such as fins, radiant heat shields, or other thermal control methods may be required to control temperature under normal and accident conditions.

Vent and Drain Port Plug and Pressure Relief Device Seals. Seals are usually provided for each vent and drain port plug and pressure relief device. The seals are required for maintaining containment in the cask under normal and accident conditions.

Vent Port Plug. Many containment-type outer storage casks and inner casks are equipped with a vent port. The port may be used for transferring gas into and out of the casks during filling with water. Gas may be purged through the port for control of gas carried contamination, radioactive gases, or gases generated by the contents of the cask. Some cask designs require the displacement of interior gas to remove or install the lid. A plug is provided to close the vent during 
transport. The plug is required to maintain containment under normal and accident conditions.

\subsubsection{Category B Items}

Gamma Shielding. Gamma Shielding is required to reduce external radiation doses to levels acceptable for storage. Lead, depleted uranium, and various steels may be used for gamma radiation shielding. The presence and effectiveness of the shielding is subject to mandatory testing during fabrication. The shielding usually performs no other function than shielding, and its presence is sufficient to satisfy its function. The shielding is usually enclosed by the inner and outer shells and, as a solid, is not subject to removal during normal conditions. Under many accident conditions, the shielding remains in place and still performs the intended function. However, some materials (e.g., lead) may melt in the event of a fire. Given that an analysis demonstrates that the expansion of the lead will not rupture containment, the molten material will remain in place unless the outer shell is breached. Therefore, two failures, loss of the outer shell and melting of the shielding, are required to prevent the shielding from performing its intended function.

Neutron Shielding. Shielding is often provided to reduce the neutron dose external to the storage system. The designs usually dictate that the neutron shielding be placed external to the gamma shielding and the outer shell. The materials of construction are often lightweight hydrocarbon materials with a high hydrogen content. This type of material typically has a low melting point and may be lost in the event of a accidental fire. It is common practice to design a cask so that neutron shielding is required for normal conditions but not required for the accident condition. Under an accident condition, the radiation dose is allowed to raise to above levels required for normal storage.

Outer Cask Outer Shell. The outer cask outer shell provides structural support for the shield material or may serve as the gamma shielding of the metal shielded type storage system. The shell may be welded to the cask bottom head and the cask shell upper head. The shell often is the outer wall of gamma shielding and sometimes is the inner wall for neutron shielding. Temperature control components such as fins are often attached to the outer shell. The outer shell may be required to maintain configuration of the cask in an accident condition. Many storage system designs will provide features that mitigate the consequences of failure of the outer shell. For example, in a containment type outer storage cask, breaching the outer shell still requires a breach of the cask inner shell before containment is breached. Many casks have gamma shielding that does not melt during the fire scenario. If the gamma shielding could melt and leak out through an outer shell breach during a fire, the design requirements may dictate that the shell should be a Category A item.

Transfer Cask. A transfer cask may be used to move the loaded and sealed inner cask between the support facility and the storage pad (concrete support pad). The transfer cask will contain gamma shielding and possibly neutron shielding. It will have a loading end cover, lifting and handling features, and may be required to operate in the vertical or horizontal mode. Because the inner cask provides containment, the transfer cask is not required to be sealed.

\subsubsection{Category C Items}

Cask Hardware. Keepers are often used as a redundant feature to prevent bolts and nuts from becoming unscrewed, pins from falling out, and lifting attachments from being improperly used. Small bolts and nuts, cotter pins, detent pins, and lockwires have been used for this function. Lanyards are often used to attach bolts and keepers to the cask to prevent misplacement of the parts. The keepers and lanyards usually do not have a direct safety implication and will not cause containment failure, loss of criticality control, or reduction of shielding capabilities if not present.

Concrete Support Pad. A concrete support pad is required to provide a stable foundation for the metal shielded storage system. The pad must maintain a level, relatively smooth surface for the cask to rest on and must withstand all normal or accident condition loads. 
Protective Cover. A protective cover and possibly some attachments may be provided for a metal shielded type of storage system. The cover serves to reduce accumulation of ice and dust from the surfaces of the cask and has no safety function.

Security Lockwire and Seals. Security lockwire and seals are used in storage systems to ensure that the contents loaded in the cask have not been tampered with. The function is a safeguard issue and not one of safety.
Shielding Shell. A thin skin of metal may be used to cover shielding. The skin allows for decontamination of a cask after underwater loading, prevents deterioration of shielding due to weather, and protects the shielding from minor damage. Temperature control devices such as fins may protrude through the skin. The skin is usually thin compared with structural components and, therefore, has negligible effect on any containment, shielding, and on criticality. 


\subsection{Concrete Shielded Type Storage Systems}

This section discusses considerations for assigning classification categories to components for a concrete shielded type system for storage of spent fuel. Figure 9 depicts a conceptual schematic of a horizontal concrete shielded system with typical components used in this type of cask, while Table 6 lists the classification categories assigned. In the concrete shielded dry spent fuel storage system, fuel is loaded into a dry shielded inner cask inside a support facility. That inner cask is then sealed and moved to the storage location in a shielded transfer cask. The inner cask is then placed inside a concrete structure for storage. This type of system may also be constructed in a vertical configuration.

\subsubsection{Category A ltems}

Basket Assembly. The basket assembly provides mechanical support for the fissile contents of the storage system. The structure is required to maintain spacing between spent fuel assemblies, and support neutron absorbers, and prevent content movement into configurations that have not been analyzed for nuclear criticality. The structure must function under normal and accident conditions.

Drain Port Plug. Most inner casks are loaded under water. Drain ports are provided for removal of water from the inner cask. A plug is provided to close each drain port. The plugs also are required to maintain containment under normal and accident conditions.

Inner Cask Bottom Head. The inner cask bottom head provides containment for the lower end of the cask under normal and accident conditions. The bottom head is welded to the inner cask shell. A single failure of this component could release radioactive material from the inner cask to areas external to the packaging.

Inner Cask Lid. The inner cask lid provides containment for the upper end of the packaging under normal and accident conditions. The lid may have closure bolt holes and sealing surfaces or it may be attached to the inner cask lid by welding. A vent port, leak check port, and a pressure relief device are usually installed in the lid. Attachments or threaded bolt holes are provided for rigging used to remotely handle the inner cask and remove the lid from the packaging. A handling grapple may be included to provide a means of inserting and removing the inner cask from the concrete structure. A shield plug may also be attach to this lid. A single failure of the lid could release radioactive material from the inner cask.

Inner Cask Lid Seals. Seals are usually used on containment lids. The seals are required for maintaining containment in the inner cask under normal and accident conditions.

Inner Cask Shell. The inner cask shell is the cylindrical wall of the removable inner cask that contains the spent fuel. The shell is typically welded to the inner cask bottom head and the inner cask shell upper head. The inner cask shell is part of the containment under normal and accident conditions. A single failure could release radioactive material outside the inner cask.

Inner Cask Shell Upper Head. The inner cask shell upper head provides containment for the upper cylindrical end of the packaging. The head may have sealing surfaces for the inner cask and threaded lid bolt holes for closure of the inner cask lid or it may be attached to the inner cask lid by welding. The head is typically welded to the inner cask shell.

Leak Check Port Plug. The leak-tight characteristics of the inner cask are tested after manufacture and as part of the loading process. In this process, gas pressures are measured and samples are taken from between the two lid seals. Similar tests are performed between inner and outer seals. In all cases, a between-seals tap is made outside the inner seal. The inner seal provides an initial level of containment. The leak check port plug and attendant seal are a second level of containment protection. Other considerations are that the plug may provide a shielding function in some inner cask designs. Often, the port has a small diameter in a deep hole and is subject to columnation of the radiation. 


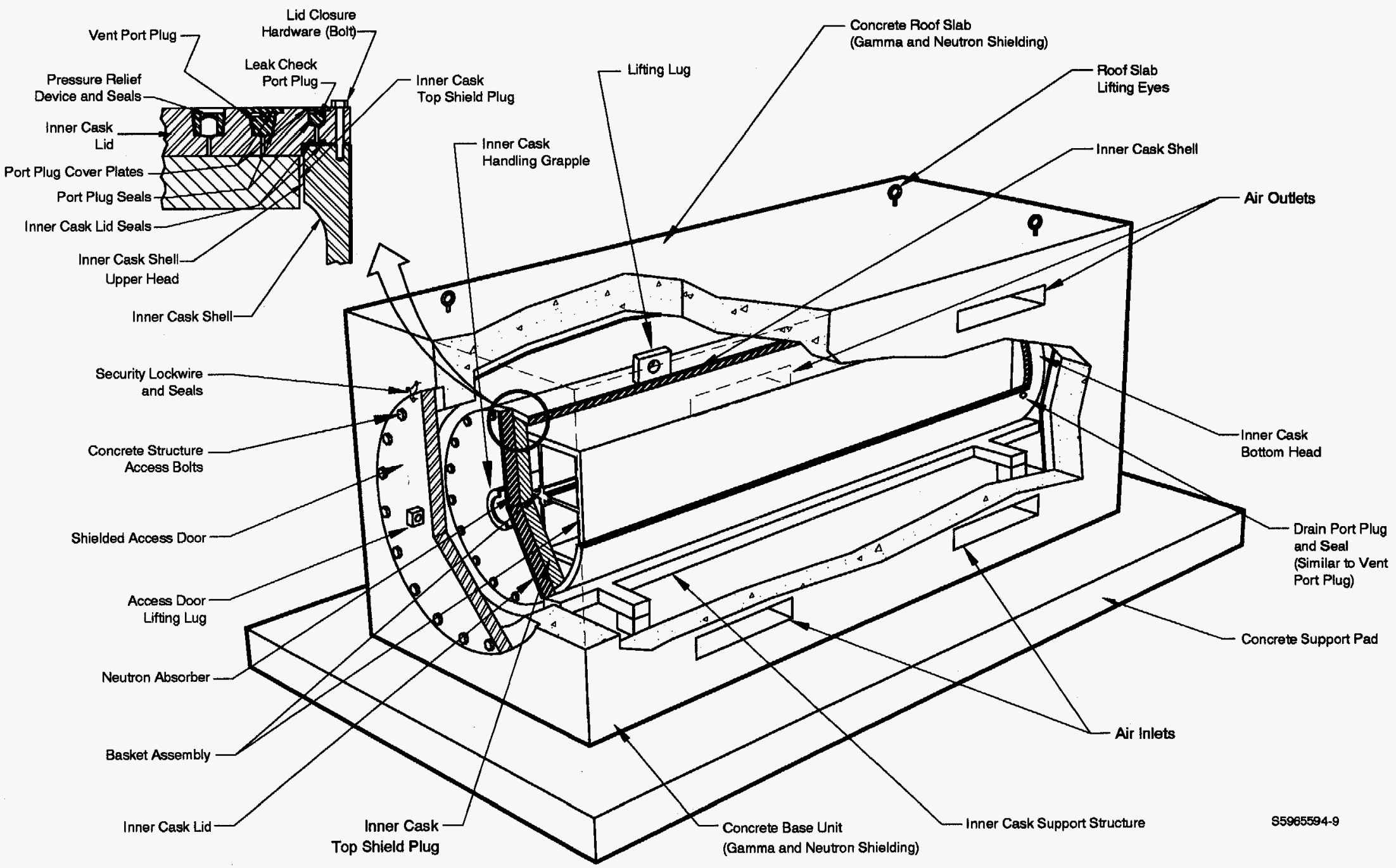

Figure 9. Schematic of a hypothetical concrete shielded type dry storage system. 
Lid Closure Hardware. Some lids are assembled to the main body of the inner cask with a number of bolts. The bolts are required for maintaining containment in the inner cask under normal and accident conditions. The failure of a single bolt is not expected to release radioactive material to uncontrolled areas. However, if inferior bolts are installed, the containment may be breached during an accident condition. Therefore, the bolts are considered as a class to be prone to a single failure.

\section{Lifting Lugs/Trunnions/Grapples. Spent} fuel storage inner casks use lifting lugs or equivalent attachments for handling inside a facility. Failure of a lifting lug may allow a breach of containment or a criticality condition. Damage to other parts of the facility are also a possibility. If the inner cask is inside a transfer device, direct radiation effects are limited to levels allowed for accident conditions. The movement of nuclear fuel in a facility is a critical lift requiring a high level of safety.

Lifting Lug/Trunnion Bolts. Bolts might be used to attach lifting lugs or other equivalent attachments to an inner cask. The bolts should have the same category as the lugs.

Neutron Absorbers. Neutron absorbers may be used for control of criticality in many dry spent fuel storage systems. Castable neutron absorbers may be used in other systems. The absorber materials are required for criticality control under normal and accident conditions.

Pressure Relief Device. Pressure relief devices are used to limit the internal pressure within the inner cask containment boundary. Pressure relief devices could include rupture disks or pressure relief valves. In addition, those devices also are required to maintain containment under normal and accident conditions.

Vent and Drain Port Plug and Pressure Relief Device Seals. Seals are usually provided for each vent and drain port plug and pressure relief device. The seals are required for maintaining containment in the inner cask under normal and accident conditions.
Vent Port Plug. Many inner casks are equipped with a vent port. The port may be used for transferring gas into and out of the inner casks during filling with water. Gas may be purged through the port for control of gas carried contamination, radioactive gases, or gases generated by the contents of the inner cask. Some inner cask designs require the displacement of interior gas to remove or install the lid. A plug is provided to close the vent during transport. The plug is required to maintain containment under normal and accident conditions.

\subsubsection{Category B Items}

Access Door Lifting Lugs. The access door lifting lugs are used to install and remove that lid. A failure of the lugs could result in significant radiation exposure to facility personnel.

Concrete Base Unit and Roof Slab. The concrete base unit and roof slab provide physical support for the storage system. The base unit includes the walls, floor, and ends, while the roof slab represents the ceiling that houses spent fuel storage casks. Shielding may be either an integral function of the structure or may be provided by other components. The structure maintains the configuration of the system under normal and accident conditions.

Concrete Structure Access Bolts. Bolts may also be used for closing the concrete structure shielded access door. Those bolts are of a secondary function.

Gamma Shielding. Gamma shielding is required to reduce external radiation doses to levels acceptable for storage. Concrete is the material used for shielding in this type of storage system. The presence and effectiveness of the shielding is subject to mandatory testing during fabrication. The shielding usually performs no other function than shielding and its presence is sufficient to satisfy its function.

Inner Cask Support Structure. The inner cask support structure provides support for the inner cask under normal and accident conditions. Failure of the structure may allow breach of the containment or a criticality condition. 
Inner Cask Top Shield Plug. An inner cask top shield plug may be required to reduce radiation exposure to operating personnel after the inner cask has been loaded into the storage cask and before the shielded access door is in place. The plug provides additional shielding in the storage mode.

Neutron Shielding. Shielding may be required to reduce the neutron dose external to the storage system. Concrete is often of sufficient thickness to suffice for neutron shielding.

Shielded Access Door. The shielded access door provides physical closure of the concrete storage system and shielding of the inner cask. The access door is held in place by the concrete structure access bolts and handled with the attached lifting lugs. Because the inner cask provides containment, the access door is not required to be sealed. The access door must remain in place to shield operations personnel in the storage mode.

Transfer Cask. A transfer cask may be used to move the loaded and sealed inner cask between the support facility and the storage pad (concrete support pad). The transfer cask will contain gamma shielding and possibly neutron shielding. It will have a loading end cover, lifting and handling features, and may be required to operate in the vertical or horizontal mode. Because the inner cask provides containment, the transfer cask is not required to be sealed.

\subsubsection{Category C Items}

Cask Hardware. Keepers are often used as a redundant feature to prevent bolts and nuts from becoming unscrewed, pins from falling out, and lifting attachments from being improperly used. Small bolts and nuts, cotter pins, detent pins, and lockwires have been used for this function. Lanyards are often used to attach bolts and keepers to the system to prevent misplacement of the parts. The keepers and lanyards usually do not have a direct safety implication and will not cause containment failure, loss of criticality control, or reduction of shielding capabilities if not present.

Concrete Support Pad. A concrete support pad is required to provide a stable foundation for the concrete shielded storage system. The pad must maintain a level, relatively smooth surface for the cask to rest on and must withstand all normal or accident condition loads.

Roof Slab Lifting Eyes. Concrete structure roof slab lifting eyes are used to move the concrete slab during construction of the structure. These eyes have no safety function when spent fuel is in storage.

Security Lockwire and Seals. Security lockwire and seals are used in storage system to ensure that the contents loaded in the cask have not been tampered with. The function is a safeguard issue and not one of safety. 
Table 6. Classification categories for dry spent fuel storage systems.

\begin{tabular}{|c|c|c|c|}
\hline Function & Component & Metal shielded & Concrete shielded \\
\hline \multirow[t]{16}{*}{ Containment $^{a}$} & Drain port plugs & A & A \\
\hline & Inner cask bottom head & A & A \\
\hline & Inner cask lid & A & A \\
\hline & Inner cask lid seals & $A$ & $A$ \\
\hline & Inner cask shell & A & A \\
\hline & Inner cask shell upper head & A & A \\
\hline & Leak check port plug & A & A \\
\hline & Lid closure hardware & A & A \\
\hline & Outer cask inner shell ${ }^{b}$ & A & - \\
\hline & Outer cask lid ${ }^{b}$ & A & - \\
\hline & Outer cask lid seals ${ }^{b}$ & A & - \\
\hline & Outer cask shell bottom head ${ }^{b}$ & A & - \\
\hline & Outer cask shell upper head ${ }^{\mathbf{b}}$ & A & 一 \\
\hline & Pressure relief device & $\mathbf{A}$ & A \\
\hline & Vent and drain port plug and pressure relief device seals & A & A \\
\hline & Vent port plug & A & A \\
\hline \multirow[t]{2}{*}{ Criticality control } & Basket assembly & $\mathbf{A}$ & A \\
\hline & Neutron absorbers & A & A \\
\hline \multirow[t]{3}{*}{ Shielding } & Gamma shielding & $\mathbf{B}^{\mathbf{c}}$ & B \\
\hline & Inner cask top shield plug & - & $\mathrm{B}^{\mathrm{c}}$ \\
\hline & Neutron shielding & $\mathbf{B}^{\mathrm{c}}$ & B \\
\hline Heat transfer & Temperature control components & A & - \\
\hline \multirow[t]{6}{*}{ Structural integrity ${ }^{d}$} & Cask hardware & $\mathrm{C}$ & $\mathbf{C}$ \\
\hline & Concrete base unit and roof slab & - & B \\
\hline & Concrete structure access bolts & - & B \\
\hline & Concrete support pad & $\mathrm{C}$ & C \\
\hline & Inner cask support structure & - & $\mathbf{B}$ \\
\hline & Outer cask outer shell & B & - \\
\hline \multirow[t]{9}{*}{ Operations support } & Access door lifting lugs & 一 & B \\
\hline & Lifting lugs/trunnions/grapples & A & A \\
\hline & Lifting lug/trunnion bolts & A & $\mathbf{A}$ \\
\hline & Protective cover & $\mathbf{C}$ & - \\
\hline & Roof slab lifting eyes & - & $\mathrm{C}$ \\
\hline & Security lockwire and seals & C & C \\
\hline & Shielded access door & - & $\mathbf{B}$ \\
\hline & Shielding shell. & C & - \\
\hline & Transfer cask & B & B \\
\hline
\end{tabular}

a. Containment boundary of the cask is defined by the parts that would be wetted if the cask interior were filled with water.

b. If the cask is used for containment boundary; however, if the cask is used only for shielding and not for containment boundary, this component may be Category $\mathrm{B}$.

c. Shielding may be Category A in specific designs.

d. Required to maintain configuration in either normal or accident conditions. 


\section{REFERENCES}

1. Title 10, Code of Federal Regulations, Part 71, "Packaging and Transportation of Radioactive Material," Office of the Federal Registrar, Washington, D.C.

2. Title 10, Code of Federal Regulations, Part 72, "Licensing Requirements for the Independent Storage of Spent Nuclear Fuel and High Level Radioactive Waste," Office of the Federal Registrar, Washington, D.C.

3. Regulatory Guide 7.10, "Establishing Quality Assurance Programs for Packaging Used in the Transport of Radioactive Material," Revision 1, U.S. Nuclear Regulatory Commission, Washington, D.C. (June 1986).

4. Regulatory Guide 7.11, "Fracture Toughness Criteria of Base Material for Verities Steel Shipping Cask Containment Vessels with a Maximum Wall Thickness of 4 inches $(0.1 \mathrm{~m})$," U.S. Nuclear Regulatory Commission, Washington, D.C., June 1991.

5. NRC Generic Letter 89-02, "Actions to Improve the Detection of Counterfeit and Fraudulently Marked Products," from S. A. Varga to All Holders of Operating Licenses and Construction Permits for Nuclear Power Reactors, dated March 21, 1989.

6. EPRI MP-5652, Guideline for the Utilization of Commercial Grade Items in Nuclear Safety Related Applications (NCIG-07), dated March 1988. 


\begin{tabular}{|c|c|}
\hline $\begin{array}{l}\text { U.S. NUCLEAR REGULATORY COMMISSION } \\
\text { BIBLIOGRAPHIC DATA SHEET } \\
\text { (See instructions on the reverse) }\end{array}$ & \multirow[t]{2}{*}{$\begin{array}{l}\text { 1. REPORT NUMBER } \\
\text { (Assigned by NRC. Add Vol,, Supp., Rev., } \\
\text { and Addendum Numbers, If any.) } \\
\text { NUREG/CR-6407 } \\
\text { INEL-95/0551 }\end{array}$} \\
\hline \multirow{4}{*}{$\begin{array}{l}\text { 2. TITLE AND SUBTITLE } \\
\text { Classification of Transportation Packaging and Dry Spent Fuel } \\
\text { Storage System Components According to Importance to Safety }\end{array}$} & \\
\hline & 3. DATE REPORT PUBLISHED \\
\hline & \begin{tabular}{|c|c|} 
MONTH & YEAR \\
February & 1996
\end{tabular} \\
\hline & $\begin{array}{l}\text { 4. FIN OR GRANT NUMBER } \\
\text { J5052 }\end{array}$ \\
\hline J.W. McConnel1, Jr., A.L. Ayers, Jr., M.J. Tyacke & $\begin{array}{l}\text { 6. TYPE OF REPORT } \\
\text { Regul atory }\end{array}$ \\
\hline & 7. PERIOD COVERED (Inalusive Dates) \\
\hline
\end{tabular}

\section{Idaho National Engineering laboratory \\ Lockheed Idaho Technologies Company \\ Idaho Falls, Idaho 83415}

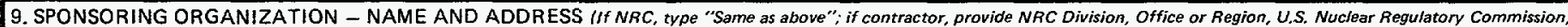
and mailing address.

Division of Industrial and Medical Nuclear Safety

Office of Nuclear Material Safety and Safeguards

U.S. Nuclear Regulatory Commission

Washington, D.C. 20555-0001

10. SUPPLEMENTARY NOTES

S.C. O'Connor, NRC Project Manager

11. ABSTRACT (200 words or less)

This report provides a graded approach for classification of components used in transportation packaging and dry spent fuel storage systems. This approach provides a method for identifying the classification of components according to importance to safety within transportation packagings and dry spent fuel storage systems. Record retention requirements are discussed to identify the documentation necessary to validate that the individual components were fabricated in accordance with their assigned classification. A review of the existing regulations pertaining to transportation packagings and dry storage systems was performed to identify current requirements. The general types of transportation packagings and dry storage systems were identified. Discussions were held with suppliers and fabricators of packagings and storage systems to determine current practices. The methodology used in this report is based on Regulatory Guide 7.10, Establishing Quality Assurance Programs for Packaging Used in the Transport of Radioactive Material. This report also includes a list of generic components for each of the general types of transportation packagings and spent fuel storage systems. The safety importance of each component is discussed, and a classification category is assigned.

12. KEY WORDS/DESCR!PTORS (List words or phrases that will assist researchers in locating the report. )

Classification Categories, Classification of Components, Dry Spent Fuel Storage Systems, Importance to Safety, Transportation Packaging

\begin{tabular}{l} 
13. AVAILABILITY STATEMENT \\
Unlimited \\
\hline 14. SECURITY CLASSIFICATION \\
This Page) \\
Uncl as s if ied \\
(This Report) \\
Unclas sified \\
\hline 15. NUMBER OF PAGES \\
\hline 16. PRICE
\end{tabular}

